\title{
Lattice Location Studies of the Amphoteric Nature of Implanted Mg in GaN
}

U. Wahl, * J. G. Correia, A. R. G. Costa, E. David-Bosne, M. J. Kappers, M. R. da Silva, G. Lippertz, T. A. L. Lima, R. Villarreal, A. Vantomme, and L. M. C. Pereira

Dr. U. Wahl, Dr. J. G. Correia, Dr. A. R. G. Costa, Dr. E. David-Bosne

Centro de Ciências e Tecnologias Nucleares, Departamento de Engenharia e Ciências

Nucleares, Instituto Superior Técnico, Universidade de Lisboa, 2695-066 Bobadela LRS, Portugal

E-mail: uwahl@ctn.tecnico.ulisboa.pt

Dr. M. J. Kappers

Cambridge Centre for Gallium Nitride

University of Cambridge

Cambridge CB3 0FS, United Kingdom

Prof. M. R. da Silva

CICECO Institute of Materials

Universidade de Aveiro

3810-193 Aveiro, Portugal

G. Lippertz

KU Leuven, Quantum Solid-State Physics, 3001 Leuven, Belgium, and Institute of Physics II, University of Cologne, 50937 Cologne

Dr. T. A. L. Lima, Dr. R. Villarreal, Prof. A. Vantomme, Prof. L. M. C. Pereira KU Leuven, Quantum Solid-State Physics, 3001 Leuven, Belgium

Keywords: GaN, Mg, acceptor doping, lattice location, ion implantation, channeling, amphoteric dopants

Despite the renewed interest in ion implantation for doping of $\mathrm{GaN}$, efficient electrical activation remains a challenge. We investigate in detail the lattice location of ${ }^{27} \mathrm{Mg}$ in $\mathrm{GaN}$ of different doping types as a function of implantation temperature and fluence at CERN's ISOLDE facility. We elucidate the amphoteric nature of $\mathrm{Mg}$, i.e. the concurrent occupation of substitutional $\mathrm{Ga}$ and interstitial sites: following room temperature ultra-low fluence $\left(\approx 2 \times 10^{10} \mathrm{~cm}^{-2}\right)$ implantation, the interstitial fraction of Mg is highest $(20-24 \%)$ in GaN predoped with stable $\mathrm{Mg}$ during growth, and lowest (2-6\%) in $n-\mathrm{GaN}: \mathrm{Si}$, while undoped nid-GaN shows an intermediate interstitial fraction of $10-12 \%$. Both for $p$ - and $n$-GaN prolonged implantations cause interstitial ${ }^{27} \mathrm{Mg}$ to approach the levels found for nid-GaN. Implanting above $400^{\circ} \mathrm{C}$ progressively converts interstitial $\mathrm{Mg}$ to substitutional $\mathrm{Ga}$ sites due to the onset 


\section{WILEY-VCH}

of $\mathrm{Mg}$ interstitial migration (estimated activation energy 1.5-2.3 eV) and combination with $\mathrm{Ga}$ vacancies. In all sample types, implantations above a fluence of $10^{14} \mathrm{~cm}^{-2}$ result in $>95 \%$ substitutional Mg. Our findings show that ion implantation is a very efficient method to introduce $\mathrm{Mg}$ into substitutional Ga sites, i.e. that the challenges towards high electrical activation of implanted $\mathrm{Mg}$ are not related to the lack of substitutional incorporation.

\section{Introduction}

During the last decades, optoelectronic devices based on the wide band gap semiconductor gallium nitride have revolutionized solid state lighting. Currently a field of applications where GaN based devices are also entering everyday life and replacing $\mathrm{Si}$ on a massive scale, is related to power electronics, ${ }^{[1-6]}$ with applications as voltage transformers or inverters, ranging from power distribution grids, electrical vehicles, photovoltaic inverters, to simple household items such as power supplies. ${ }^{[7]}$ The vast majority of GaN-based devices require besides $n$ type also $p$-type doping, and it is well-known that the group-II element $\mathrm{Mg}$ is the only technologically feasible acceptor dopant in GaN. ${ }^{[3-5,8]}$ Yet, $\mathrm{Mg}$ doping suffers from a number of limitations, most notably the deep nature of the acceptor level at $\approx 245 \mathrm{meV},{ }^{[9]}$ which means that high dopant concentrations have to be incorporated in order to realize the hole concentrations required in the devices. Hydrogen passivation related to $\mathrm{Mg}-\mathrm{H}$ complex formation is another issue, ${ }^{[10-12]}$ as well as compensation by native donors, ${ }^{[10,13]}$ the tendency of $\mathrm{Mg}$ to form clusters, ${ }^{[14]}$ and its amphoteric nature. ${ }^{[11-13]}$ The latter concerns its ability to occupy both substitutional Ga and interstitial sites, which can lead to self-compensation and is of particular concern at the high doping levels $>10^{19} \mathrm{~cm}^{-3}$ needed in some electrical devices. Many of the power devices also require selective area doping, ${ }^{[3-5,8]}$ which has greatly renewed the interest in ion implantation as a technique to introduce dopants into $\mathrm{GaN}$ since it allows precise transverse and lateral control of dopant concentrations. Already in the early days of $\mathrm{GaN}$ research, ion implantation of $\mathrm{Mg}$ has been investigated in order to achieve $p$-type 


\section{WILEY-VCH}

doping, ${ }^{[15-18]}$ however, with limited success. The biggest obstacle for $p$-type ion implantation doping of $\mathrm{GaN}$ is considered to be electrical activation of the implanted $\mathrm{Mg}$ and removal of radiation damage. This requires temperatures well above $960^{\circ} \mathrm{C}$, where $\mathrm{N}$ starts escaping from the GaN surface, which is usually suppressed by covering it with a protective layer of AlN, $\mathrm{SiN}$ or $\mathrm{SiO}_{2}$ during annealing. Recently, a number of novel approaches using $\mathrm{Mg}$ ion implantation and annealing have achieved very promising results regarding $p$-type doping, e.g. multicycle rapid thermal annealing (RTA) ${ }^{[19]}$ high-temperature implantation around $500^{\circ} \mathrm{C}^{[19-21]}$ or $1000^{\circ} \mathrm{C}^{[22]}$ ultra-high-pressure annealing, ${ }^{\left[{ }^{[, 23-24]}\right.}$ microwave annealing, ${ }^{[21]}$ pulsed laser annealing, ${ }^{[25]}$ or co-implantation of N. ${ }^{[26]}$ However, also conventional RTA ${ }^{[20,27,28]}$ or furnace annealing ${ }^{[29,30]}$ has been reported successful and suitable for creating devices such as visible-blind photodiodes ${ }^{[29]}$ or power rectifiers. ${ }^{[30]}$ A crucial step for the electrical activation of the group II element $\mathrm{Mg}$ is its incorporation on substitutional Ga sites, since only in this lattice position it can act as an acceptor. The occupancy of other lattice sites, as e.g. in Mg clusters, can leave it in an electrically inactive state, or worse, lead to self-compensation of $\mathrm{Mg}_{\mathrm{Ga}}$ acceptors by interstitial $\mathrm{Mg}_{\mathrm{i}}$ double donors. ${ }^{[11-13]}$ While the amphoteric nature of $\mathrm{Mg}$ was long disputed, ${ }^{[10-13]}$ we have recently established the co-existence of $\mathrm{Mg}$ in substitutional $\mathrm{Ga}$ and interstitial near-octahedral sites in GaN samples of different doping types. ${ }^{[31]}$ Besides a dominant fraction of $\mathrm{Mg}$ on substitutional Ga sites, we identified minority fractions on sites located in the wide-open interstitial region of the $\mathrm{GaN}$ wurtzite lattice, displaced $-0.6 \AA$ parallel to the $c$-axis from the ideal octahedral (O) sites, cf. Supporting Information. The amphoteric nature of $\mathrm{Mg}$ is a characteristic it shares with $\mathrm{Li}, \mathrm{Na}$, and $\mathrm{Be}$ and thus fits well into the general picture of how light alkalis and alkaline earths behave in $\mathrm{GaN}^{[32-33]}$ and it was also found in AlN. ${ }^{[34]}$ While the present study is motivated by the recent interest in ion implantation doping with $\mathrm{Mg}$, which we address by providing lattice location results as a function of implantation temperature and fluence up to the technology relevant fluence regime above $10^{14} \mathrm{~cm}^{-2}$, we 


\section{WILEY-VCH}

also clarify pertinent fundamental properties of this dopant. In particular we further elucidate the amphoteric nature of $\mathrm{Mg}$ by identifying how the initial doping type of the sample influences the $\mathrm{Mg}$ lattice location and what happens when the doping type is being changed on a time scale of minutes by the introduction of radiation damage resulting from implanted fluences of $5 \times 10^{10} \mathrm{~cm}^{-2}$ up to $4 \times 10^{14} \mathrm{~cm}^{-2}$, i.e. spanning four orders of magnitude. We also provide additional data regarding the interstitial diffusion of Mg. Finally, a Fermi-level model is proposed, which takes into account band-bending near the GaN surface and allows to qualitatively explain the lattice location of $\mathrm{Mg}$ as a function of implanted fluence in different doping types.

For determining the lattice location of $\mathrm{Mg}$, we used the electron emission channeling (EC) method ${ }^{[35-38]}$ from the radioactive isotope ${ }^{27} \mathrm{Mg}\left(t_{1 / 2}=9.45 \mathrm{~min}\right)$. In EC experiments, radioactive probe atoms are implanted at low fluences (typically $10^{11}-10^{13} \mathrm{~cm}^{-2}$ ) into singlecrystalline samples, where, occupying specific lattice sites, they subsequently decay by the emission of $\beta^{-}$particles. The $\beta^{-}$particles are guided by the crystal potential on their way out of the sample, which results in angular-dependent emission yields around major crystallographic directions that are characteristic for the lattice site(s) that the probe atoms occupy during their decay. The emission patterns are recorded by means of a two-dimensional position-sensitive detector. ${ }^{[36-37]}$ The major lattice sites can be identified by fitting the experimentally observed angular-dependent emission yields by linear combinations of theoretically expected patterns for specific positions in the lattice. ${ }^{[36-37,39]}$

\section{Results and Discussion}

The characteristics of the four different doping types of $\mathrm{GaN}$ layers used were described in more detail in Ref. ${ }^{[31]}$. They are, in brief, $i$ ) not intentionally doped epilayers (nid-GaN), ii) $n$ GaN:Si layers doped with $1 \times 10^{19} \mathrm{~cm}^{-3} \mathrm{Si}$, and layers doped during growth with $2 \times 10^{19} \mathrm{~cm}^{-3}$ Mg. However, while iii) "GaN:Mg” samples were used as-grown, iv) “ $p$-GaN:Mg” samples 


\section{WILEY-VCH}

were annealed for $20 \mathrm{~min}$ at $800^{\circ} \mathrm{C}$ under nitrogen atmosphere in order to drive out $\mathrm{H}$ and electrically activate the $\mathrm{Mg}$, typically leading to hole concentrations of $1-2 \times 10^{17} \mathrm{~cm}^{-3}$ and Hall mobilities of $10-15 \mathrm{~cm}^{2} \mathrm{~V}^{-1} \mathrm{~s}^{-1} \cdot{ }^{[40]}$

For the present study, only [0001] (c-axis) patterns were measured, since these allow to quantify with high accuracy the relative amounts of interstitial vs substitutional ${ }^{27} \mathrm{Mg}$. The orientation of the samples was thus kept fixed during most of the measurements, except when moving the samples laterally in order to change to new beam spots for measuring the detailed fluence dependence at different temperatures.

Rather than estimating the "absolute" fraction $f_{i}$ of interstitial ${ }^{27} \mathrm{Mg}_{\text {i, }}$, i.e. the number of interstitial ${ }^{27} \mathrm{Mg}_{\mathrm{i}}$ relative to the number of total implanted ${ }^{27} \mathrm{Mg}$ ions, we report in the following the "relative fraction" $f_{\mathrm{i}} /\left(f_{\mathrm{i}}+f_{\mathrm{S}}\right)$, which is the number of interstitial ${ }^{27} \mathrm{Mg}_{\mathrm{i}}$ divided by the sum of interstitial ${ }^{27} \mathrm{Mg}_{\mathrm{i}}$ plus substitutional ${ }^{27} \mathrm{Mgs}_{\mathrm{s}}$. This has the advantage that the relative fractions, which can be determined with an accuracy in the per cent range, are not influenced, e.g., by variations in the background of the measurements over time. These are particularly relevant in on-line experiments where short-lived isotopes are continuously implanted and changes in beam characteristics such as focusing (e.g. resulting from modifications in ion source conditions) can alter the signal to background ratio. Since such variations cannot be continuously monitored and therefore not precisely taken into account during analysis, they lead to fluctuations larger than $5 \%$ in the fitted absolute fractions $f_{\mathrm{i}}$ and $f_{\mathrm{S}}$, which are thus eliminated by instead considering the relative fraction $f_{\mathrm{i}} /\left(f_{\mathrm{i}}+f_{\mathrm{S}}\right)$. Since we found no indications for a third type of lattice site to be occupied, and the amount of ${ }^{27} \mathrm{Mg}$ on random lattice sites is small, ${ }^{[31]}$ the absolute interstitial fractions $f_{\mathrm{i}}$ are quite similar to the relative fractions $\left.f_{\mathrm{i}} /\left(f_{\mathrm{i}}+f_{\mathrm{S}}\right)\right)$, though subject to larger errors and variations (estimated $\pm 5 \%$ ).. A discussion on backgroundcorrected sum fractions $f_{\mathrm{i}}+f_{\mathrm{S}}$ can be found in the Supporting Information. 


\section{WILEY-VCH}

\section{[0001]}

experiment

best fit

(a) $n-\mathrm{GaN}: \mathrm{Si}$
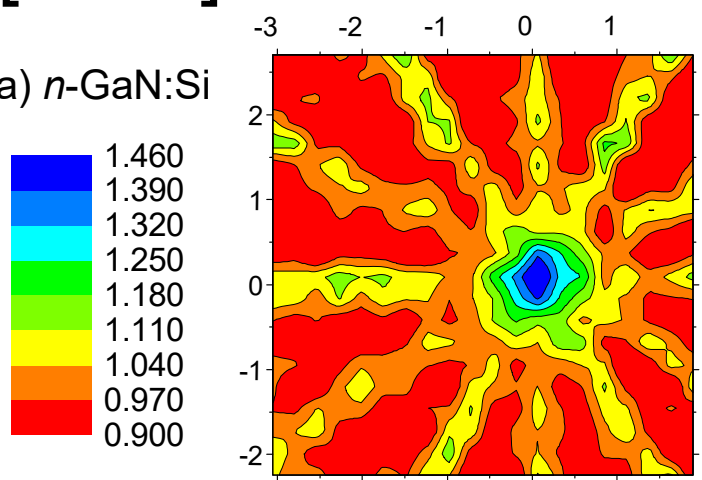
$\begin{array}{lllll}-3 & -2 & -1 & 0 & 1\end{array}$

(b) $p-\mathrm{GaN}: \mathrm{Mg}$
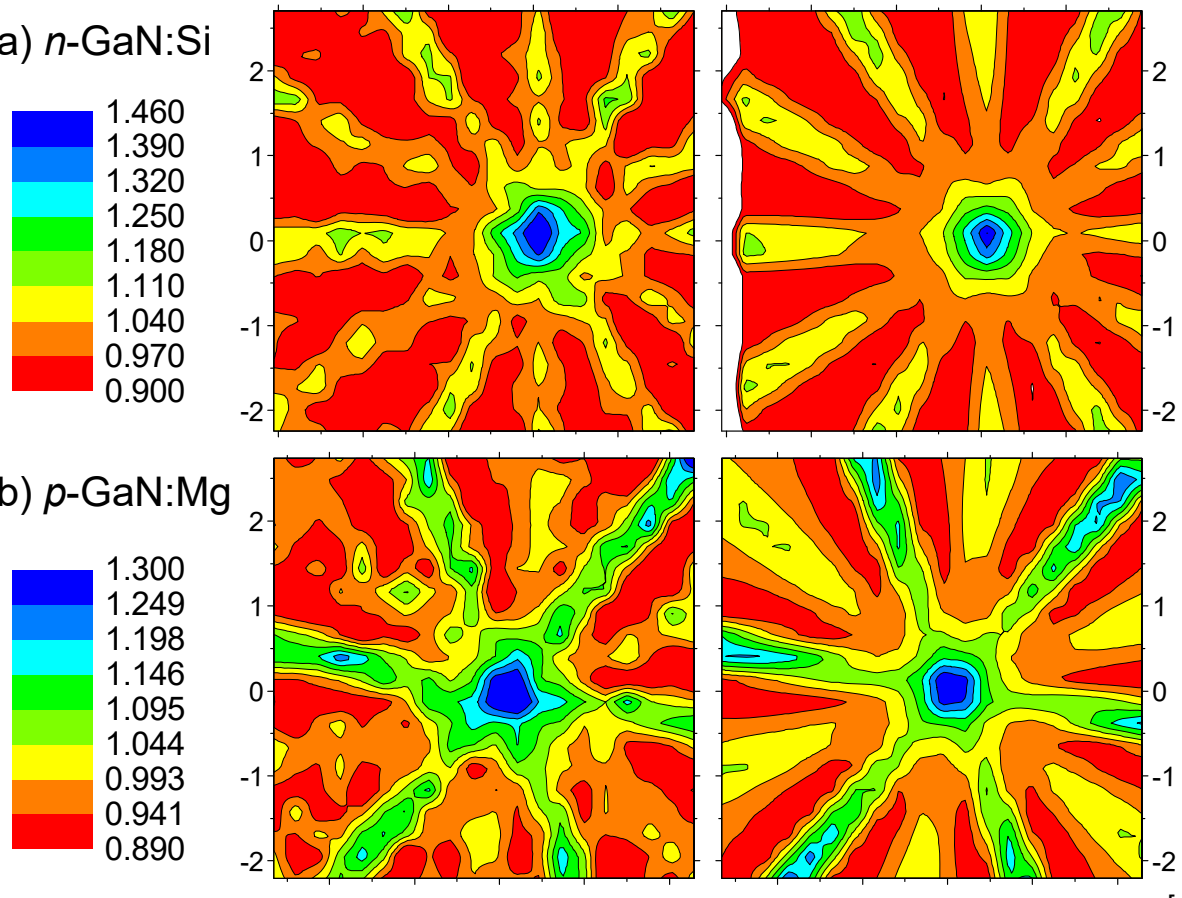

(c) $5 \% \mathrm{Mg}_{\mathrm{i}}$
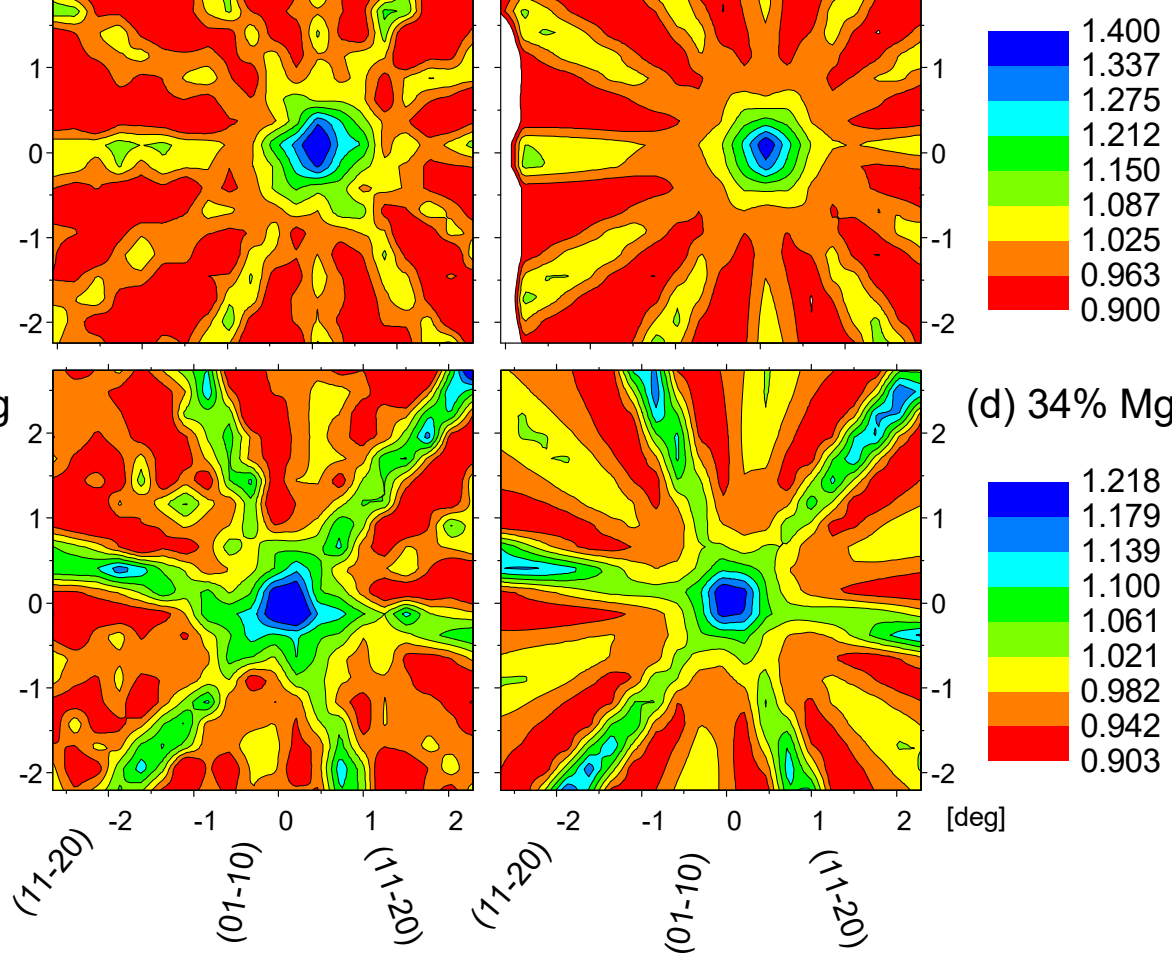

(d) $34 \% \mathrm{Mg}_{\mathrm{i}}$

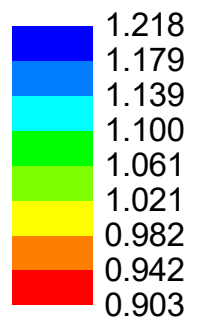

Figure 1. [0001] experimental $\beta^{-}$emission channeling patterns from ${ }^{27} \mathrm{Mg}$ in (a) $n-\mathrm{GaN}: \mathrm{Si}$, $T_{\mathrm{i}}=\mathrm{RT}$, and (b) $p$-GaN:Mg, $T_{\mathrm{i}}=300^{\circ} \mathrm{C}$. Panels (c) and (d) are the corresponding best fits of theoretical patterns considering substitutional sites $\mathrm{S}$ located along and interstitial sites parallel to the $c$-axis. The fitted relative interstitial fractions, $f_{i}\left(f_{\mathrm{i}}+f_{\mathrm{S}}\right)$, are $5 \%$ in case of $n$ $\mathrm{GaN}: \mathrm{Si}$ and $34 \%$ in case of $p-\mathrm{GaN}: \mathrm{Mg}$. Each of the experimental patterns corresponds to an implanted fluence of $4.8 \times 10^{10} \mathrm{~cm}^{-2}$ and they were obtained during 9 min at count rates of 560 events s${ }^{-1}$, total 303622 events ( $\left.n-\mathrm{GaN}: \mathrm{Si}\right)$, and $90 \mathrm{~s}$ at 3300 events $\mathrm{s}^{-1}$, total 298549 events ( $p$-GaN:Mg). They represent the first data points for the corresponding implantation temperatures in Figure 2(a) and 2(d).

Figure 1(a) shows the normalized angular distribution of $\beta^{-}$particles emitted around the [0001] direction of an $n$-GaN:Si sample during room temperature (RT) implantation of ${ }^{27} \mathrm{Mg}$, 


\section{WILEY-VCH}

while Figure 1(b) is the corresponding distribution from $p-\mathrm{GaN}: \mathrm{Mg}$ for an implantation temperature of $T_{\mathrm{i}}=300^{\circ} \mathrm{C}$. Figure $1(\mathrm{c})$ and (d) represent the best fits of a linear combination of theoretical patterns from ${ }^{27} \mathrm{Mg}$ aligned with the $c$-axis (as is the case for substitutional $\mathrm{Ga}$ sites) and interstitial to it, which were obtained for relative interstitial fractions $f_{\mathrm{i}} /\left(f_{\mathrm{i}}+f_{\mathrm{S}}\right)$ of $5 \%$ for $n-\mathrm{GaN}: \mathrm{Si}$ and 34\% for $p$-GaN:Mg. Although these fractions are determined based on numerical fitting, the effect of considerable amounts of ${ }^{27} \mathrm{Mg}$ on interstitial sites (in $p$ GaN:Mg) on our data is so strong that it can even be qualitatively illustrated by the following. The pattern in Figure 1(a) is largely dominated by substitutional sites, for which the sets of planar directions (11-20) and (01-10) exhibit similar intensity of channeling effects. For interstitial sites, the [0001] axial and the planar (01-10) effects are characterized by blocking rather than channeling effects (cf. the simulated patterns shown in Figure $\mathbf{S 2}$ of the Supporting Information). Therefore, the channeling intensities of these directions are considerably reduced in Figure 1(b), in particular the axial effect is $35 \%$ weaker compared to Figure 1(a).

Figure 2 displays the fitted relative interstitial fractions of ${ }^{27} \mathrm{Mg}_{\mathrm{i}}$ plotted as a function of the number of recorded detector events throughout experiments with samples of all doping types, with the various colors representing different implantation temperatures. While the number of recorded events can be translated directly into implanted fluences of ${ }^{27} \mathrm{Mg}$ [every $1 \times 10^{7}$ events correspond to an implanted ${ }^{27} \mathrm{Mg}$ fluence of $1.6 \times 10^{12} \mathrm{~cm}^{-2}$; significantly higher fluences can only be reached using stable isotope implantations, as discussed below under point $\mathrm{c}$ )], it is important to point out that for each implantation temperature a fresh beam spot on the sample was chosen. Note that Figure $\mathbf{S 3}$ of the Supporting Information contains some more such data measured with additional $n-\mathrm{GaN}: \mathrm{Si}$, nid-GaN, and $p$-GaN:Mg samples. In the following we will point out the major visible features and discuss their physical interpretation. 
WILEY-VCH
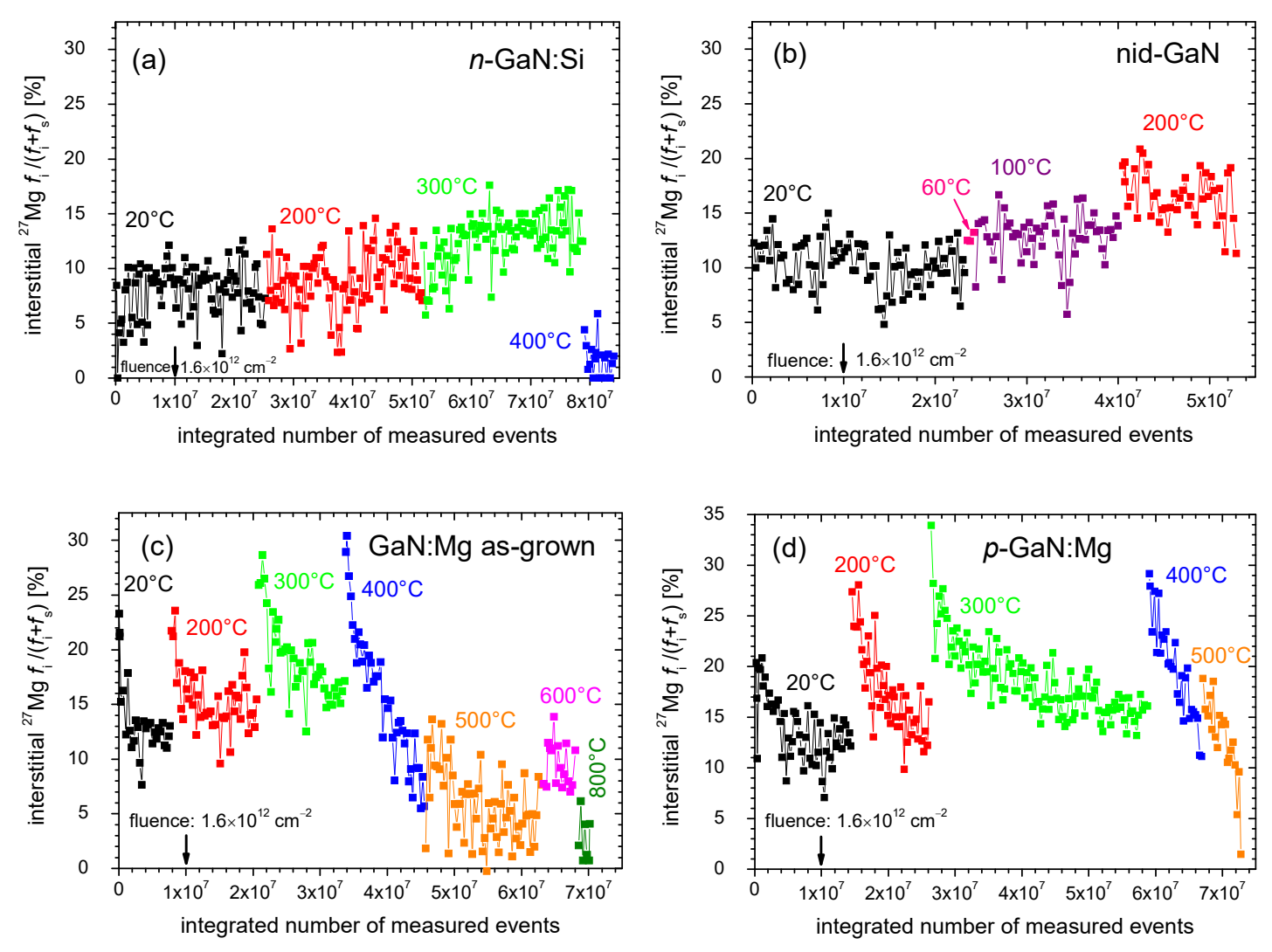

Figure 2. Relative amounts of interstitial ${ }^{27} \mathrm{Mg}_{\text {i }}$ for various implantation temperatures as a function of the integrated number of measured events during $50 \mathrm{keV}$ experiments in (a) $n$ $\mathrm{GaN}: \mathrm{Si}$, (b) nid-GaN, (c) as-grown GaN:Mg, and (d) $p$-GaN:Mg. Note that for each implantation temperature a fresh beam spot was chosen. Thus, while every $1 \times 10^{7}$ events correspond to an implanted ${ }^{27} \mathrm{Mg}$ fluence of $1.6 \times 10^{12} \mathrm{~cm}^{-2}$, as indicated by the black arrows, the overall number of implanted $\mathrm{Mg}$ atoms did not accumulate in a single spot on the sample.

a) For repeated measurements on short time scales (each data point in Figure 2 corresponds to around 250000-300000 events/pattern and measuring times of several minutes), the relative fractions of interstitial ${ }^{27} \mathrm{Mg}_{\mathrm{i}}$ (Figure 2 and S3) show rather large fluctuations, on the order of $\pm 5 \%$, that cannot be explained by statistical uncertainty alone since the statistical errors in the fraction fit parameter of each of the measurements are on the order of $\pm 1.5 \%$. However, in some cases the amount of interstitial ${ }^{27} \mathrm{Mg}_{\mathrm{i}}$ seems to alternate between two states; this effect is 


\section{WILEY-VCH}

particularly visible for the RT implantations in $n$-GaN or nid-GaN [Figure 2(a) and 2(b)]. In other cases, there are signs of oscillations or "beats" with a periodicity around 2$5 \times 10^{6}$ recorded events. We believe that these phenomena result from the build-up of positive charges in the near-surface layer of the samples. Such charges originate from three processes: i) the implantation of positively charged ${ }^{27} \mathrm{Mg}^{+}$ions, ii) the emission of secondary electrons $\mathrm{e}^{-}$ upon the impact of ${ }^{27} \mathrm{Mg}^{+}\left(\approx 3.5 \mathrm{e}^{-}\right.$per implanted ion), iii) the emission of $\beta^{-}$particles from the sample due to the radioactive decay of ${ }^{27} \mathrm{Mg}$. The conjunction of these three processes causes positive charging up of the near-surface layers and the region where implanted $\mathrm{Mg}$ ions come to rest. How fast the positive charges are removed depends on the electric fields that build up inside the sample, its conductivity and how well it is electrically connected to the sample holder. Since the epitaxial GaN layers are deposited on insulating sapphire, most likely the charges have to flow out laterally towards where the layers are clamped to the electrically conductive sample holder. This process may be slow and subject to oscillations that result from the build-up of lateral electric fields inside the layer and quasi-periodic discharges. Since the existence of positive surface charges leads to a downward bending of the GaN energy bands as illustrated in Figure 3, the near-surface region of the sample will appear more $n$ type, i.e. with the Fermi level closer to the conduction band, as long as the charges are present, and return towards undoped or more $p$-type once the charges have been removed. This may lead to quasi-periodic changes in the interstitial fraction of ${ }^{27} \mathrm{Mg}$ if the latter, due to its amphoteric nature, depends on the position of the Fermi level. For an $n$-type GaN sample implanted at $20 \mathrm{keV}$, hence with a shallower $\mathrm{Mg}$ depth profile, the interstitial amount of $\mathrm{Mg}$ was 2-3\% lower [Figure S3(a)] than for $50 \mathrm{keV}$ implantation, thus the sample appeared more $n$-type. For a $p$-type sample, $20 \mathrm{keV}$ implantation did not profoundly change the interstitial fraction, however, the fluctuations were found to be more intense [Figure S3(d)]. It is wellknown that without artificial surface charges there is an upward band-bending around $+1.5 \mathrm{eV}$ 
for $n$-GaN and downward $-1.6 \mathrm{eV}$ for $p-\mathrm{GaN} .^{[41-43]}$ If our hypothesis is correct, the effect of the implantation-induced surface charges seems to override these natural band-bendings. We also checked for a possible influence of the fluence rate of implantations by varying the ${ }^{27} \mathrm{Mg}$ beam current over an order of magnitude, but no such effect was found.

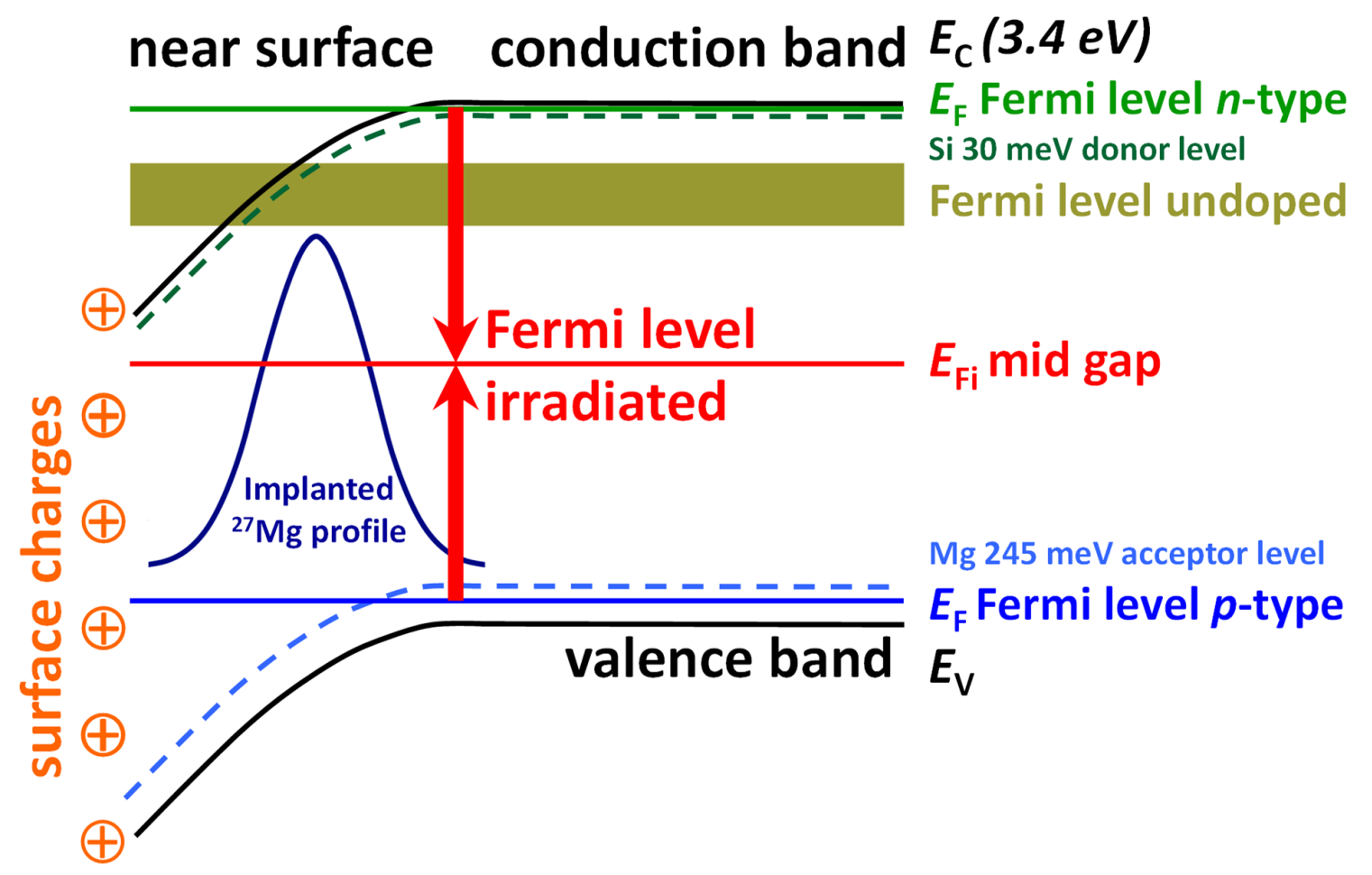

Figure 3. GaN band gap, levels of electrical dopants $\mathrm{Si}$ and $\mathrm{Mg}$, and schematic Fermi level positions in $n$-type, $p$-type, undoped and irradiated material. The attribution of the Fermi level $E_{\mathrm{Fi}}$ at mid gap in irradiated $\mathrm{GaN}$ is tentative. The Gaussian profile schematically indicates the depth distribution of implanted ${ }^{27} \mathrm{Mg}$ where it may be subject to the influence of positive surface charges which cause band bending near the GaN surface. Note that without artificial surface charges there is an upward band-bending around $+1.5 \mathrm{eV}$ for $n-\mathrm{GaN}$ and downward $-1.6 \mathrm{eV}$ for $p-\mathrm{GaN} .^{[41-43]}$ 
b) In $p$-type GaN:Mg [Figure 2(d) and S3(d)], during RT implantation of $1.3 \times 10^{12} \mathrm{~cm}^{-2}$ of

${ }^{27} \mathrm{Mg}\left(8 \times 10^{6}\right.$ events $)$ the relative interstitial fraction decreased from $18-20 \%$ to approximately the $\approx 10-12 \%$ level found for undoped GaN [Figure 2(b) and S3(c)]; in as-grown Mg-doped GaN [Figure 2(c)], a similar decrease occurred but already at a fluence of $4 \times 10^{11} \mathrm{~cm}^{-2}$ $\left(2.5 \times 10^{6}\right.$ events), i.e. more than three times faster. These effects can be explained by the Fermi level dependence of interstitial vs substitutional Mg preference as follows. Radiation damage resulting from the ${ }^{27} \mathrm{Mg}$ implantation introduces a variety of electrical levels into the band gap of $\mathrm{GaN}$. As in most other semiconductors, also in GaN irradiation damage leads to charge compensation ${ }^{[16-18]}$ and thus tends to move the Fermi level towards the mid gap position, as is illustrated in Figure 3. GaN samples that were initially $p$-type will thus move towards an intrinsic state as more and more ${ }^{27} \mathrm{Mg}$ ions are implanted. For not intentionally doped nid-GaN, the changes in interstitial ${ }^{27} \mathrm{Mg}$ fractions as a function of implanted fluence [Figure 2(b), S3(c) and 4(b)] are not very pronounced, if averaged over longer measurements. In $p$-type $\mathrm{GaN}$, however, the Fermi level will move upwards as a consequence of the ${ }^{27} \mathrm{Mg}$ implantation defects, thus causing progressive loss of the $p$-type character and a lowering of the ${ }^{27} \mathrm{Mg}_{\mathrm{i}}$ interstitial fraction. This indicates that the as-grown $\mathrm{Mg}$-doped $\mathrm{GaN}$ sample was also $p$-type but with a considerably smaller hole concentration than the sample where $\mathrm{Mg}$ was electrically activated by post-growth annealing. In $n$-type $\mathrm{GaN}: \mathrm{Si}$, interstitial ${ }^{27} \mathrm{Mg}_{\mathrm{i}}$ fractions are initially smallest, around $2-6 \%$ only, and show an increase with implanted fluence [Figure 2(a), S3(a), and 4(a)], for $\approx 1 \times 10^{12} \mathrm{~cm}^{-2}$ of implanted ${ }^{27} \mathrm{Mg}\left(7 \times 10^{6}\right.$ events $)$ at RT reaching similar levels as in nid-GaN. We interpret this as the $n$-type character of the sample being changed by implantation towards intrinsic conditions.

c) When the fluence of implanted $\mathrm{Mg}$ is increased above several $10^{13} \mathrm{~cm}^{-2}$ by means of implanting the stable isotopes ${ }^{24} \mathrm{Mg},{ }^{25} \mathrm{Mg}$ or ${ }^{26} \mathrm{Mg}$, the interstitial fractions of ${ }^{27} \mathrm{Mg}$ found in subsequent implantations of this radioisotope are significantly and progressively reduced to a 
WILEY-VCH

few per cent only (Figure 4 and S4). This happens irrespective of the initial doping type of the sample, which at such high implanted fluences quite likely has been converted to intrinsic conditions. We interpret this fact as due to an increase in the concentration of Ga vacancies $V_{\text {Ga }}$ with $\mathrm{Mg}$ fluence, which increases the probability that newly implanted ${ }^{27} \mathrm{Mg}$ is incorporated on substitutional Ga sites instead of staying in an interstitial position. While no studies on the damage accumulation in $\mathrm{GaN}$ for $10^{13}-10^{14} \mathrm{~cm}^{-2} \mathrm{RT}$ implantation of ions with masses similar to ${ }^{27} \mathrm{Mg}$ are to be found in the literature, it has been reported that following ${ }^{40} \mathrm{Ar}$ implantation the number of displaced host atoms increases linearly with fluence in this range. ${ }^{[44,45]}$ It is hence plausible to assume that this also applies to the case of $V_{\text {Ga }}$ defects following Mg implantation. Our interpretation is also supported by the fact that a linear relation between $\mathrm{Mg}$ fluence and $V_{\mathrm{Ga}}$ can well explain the interstitial fractions of $\mathrm{Mg}$ as function of fluence observed at RT, as will be detailed below following point d).

d) Irrespective of the doping type of the sample, the amount of interstitial ${ }^{27} \mathrm{Mg}_{\mathrm{i}}$ always increases when the implantation temperature is raised above RT until reaching $300-400^{\circ} \mathrm{C}$ (Figure 2 and 4, also prominently visible in Figure 5). This can be explained by the fact that due to dynamic annealing during the implantation process at elevated temperatures less Ga vacancies are available in the sample, which increases the probability that ${ }^{27} \mathrm{Mg}$ remains in interstitial sites. In Mg-doped GaN, there should also be a second mechanism at work: the general reduction of implantation damage at higher temperatures means in this case that also the initial spike in the interstitial $\mathrm{Mg}$ fraction, that is related to the $p$-type character of the samples, is revealed more profoundly. 
WILEY-VCH
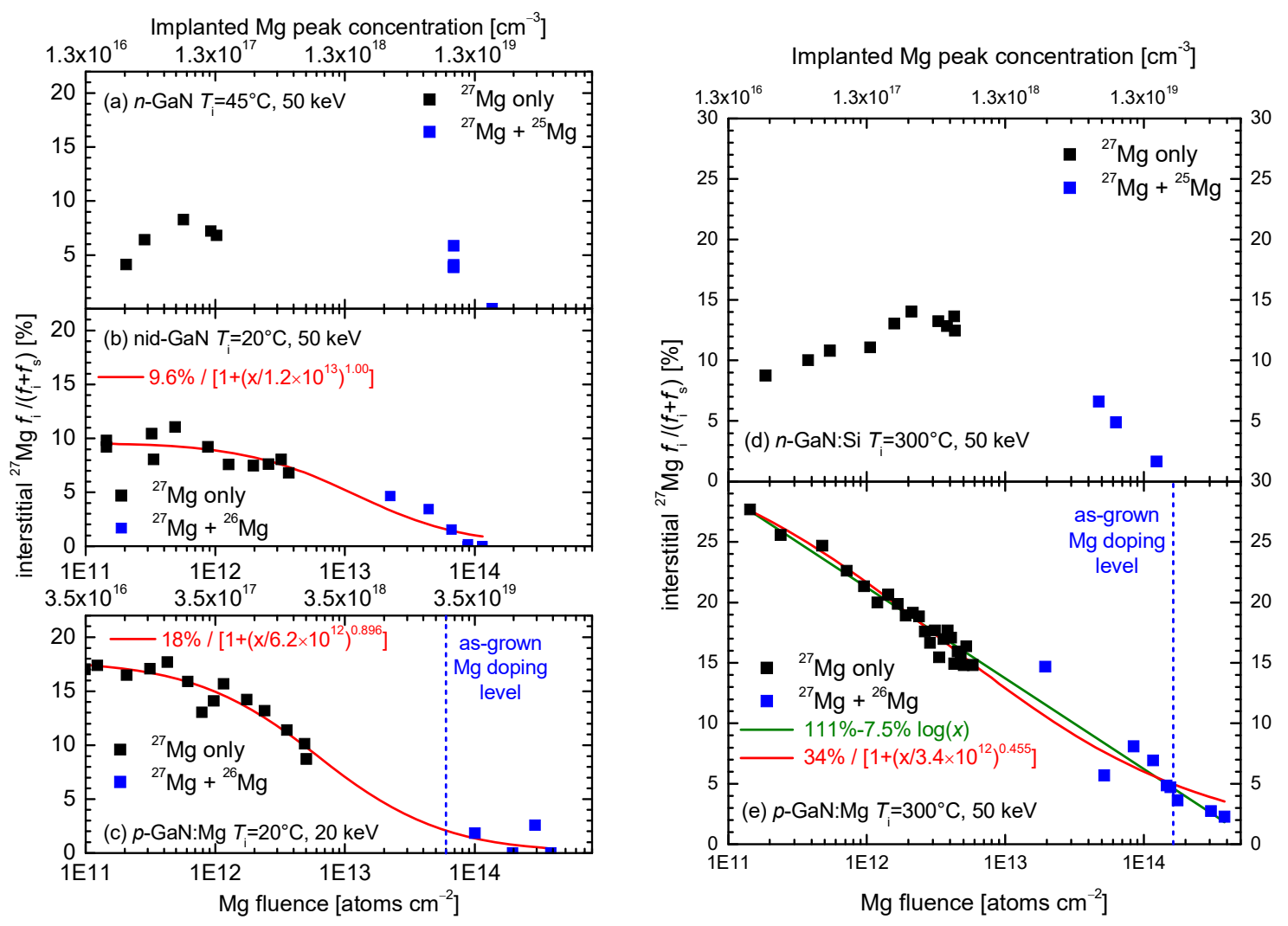

Figure 4. Relative amount of interstitial ${ }^{27} \mathrm{Mg}$ as a function of $\mathrm{Mg}$ fluence in different types of samples (a) $n$-GaN:Si, (b) nid-GaN, and (c) $p$-GaN:Mg, all for RT implantation or slightly above; (d) $n$-GaN:Si and (e) $p$-GaN:Mg for implantation at $300^{\circ} \mathrm{C}$. The black data points correspond to implantation of radioactive ${ }^{27} \mathrm{Mg}$ only, while the ones in blue are following additional implantation steps of the stable isotopes ${ }^{25} \mathrm{Mg}$ or ${ }^{26} \mathrm{Mg}$. Note the logarithmic scale for the $\mathrm{Mg}$ fluence. The concentrations of implanted $\mathrm{Mg}$ in the peak of the implantation profile are indicated at the top axes of the figures, the one in panel (c) being different from (a) and (b) due to the lower implantation energy of $20 \mathrm{keV}$. The blue vertical lines in (c) and (e) show the $\mathrm{Mg}$ concentration $2 \times 10^{19} \mathrm{~cm}^{-3}$ resulting from the doping of this sample during growth. The fitted curves are discussed in the text.

The combination of the effects described in b) to d) is particularly well visible when comparing the relative fractions of interstitial ${ }^{27} \mathrm{Mg}_{\mathrm{i}}$ measured as a function of $\mathrm{Mg}$ fluence at 


\section{WILEY-VCH}

an implantation temperature of $300^{\circ} \mathrm{C}$ in $n$-GaN:Si and $p$-GaN:Mg. In $n$-GaN:Si [Figure 4(d)] the relative interstitial fraction exhibits a value of $9 \%$ for the low fluence of $2 \times 10^{11} \mathrm{~cm}^{-2}$ and increases up to $\approx 13-14 \%$ once $2 \times 10^{12} \mathrm{~cm}^{-2}$ is reached. The implantation of stable ${ }^{25} \mathrm{Mg}$ then progressively reduces the relative interstitial fraction to below $2 \%$ above $1 \times 10^{14} \mathrm{~cm}^{-2}$. On the contrary, in $p$-GaN:Mg [Figure 4(e)], at the fluence of $1.4 \times 10^{11} \mathrm{~cm}^{-2}$ the relative interstitial fraction exhibits the high value of $28 \%$ (note that the initial transient due to loss of $p$-type character is not shown in this plot) and drops continuously to values around $2 \%$ when increasing the implantation fluence up to $3.8 \times 10^{14} \mathrm{~cm}^{-2}$. This continuous decrease of the interstitial fraction was found to be approximately proportional to the logarithm of the implanted fluence, as is illustrated by the green line in Figure 4(e): within the fluence range considered in the plot, for each increase in the implanted Mg fluence by a factor of 10 , the interstitial ${ }^{27} \mathrm{Mg}$ fraction $f_{\mathrm{i}}$ decreased by $\approx 7.5 \%$. However, if we denote with $C$ the concentration of available gallium vacancies $V_{\mathrm{Ga}}$, one would expect for $f_{\mathrm{i}}$ a functional dependency of the form ${ }^{[46]}$

$f_{\mathrm{i}}(C)=f_{\mathrm{i} 0} \frac{1}{1+4 \pi \tau R D C}$

where $\tau$ is the radioactive life time of ${ }^{27} \mathrm{Mg}, D$ the sum of the diffusivities of $\mathrm{Mg}_{\mathrm{i}}$, and $V_{\mathrm{Ga}}$ and $R$ the capture radius of $V_{\mathrm{Ga}}$ and $\mathrm{Mg}_{\mathrm{i}}$. Assuming that the concentration $C$ of $V_{\mathrm{Ga}}$ is proportional to the implanted fluence $\Phi$, one obtains

$f_{\mathrm{i}}(\Phi)=f_{\mathrm{i} 0} \frac{1}{1+\Phi / \Phi_{\mathrm{t}}}$

where $\Phi_{t}$ is a constant of dimension $\mathrm{cm}^{-2}$ that marks the turning point of the curve. The best fit of $f_{\mathrm{i}}(\Phi)$ that can be obtained using this functional form is shown in Figure $\mathbf{S 5}$ of the Supporting Information. As can be seen, such a simple capture model based on the assumption that the concentration of Ga vacancies in the sample is proportional to the 


\section{WILEY-VCH}

implanted Mg fluence, cannot be used to fit the whole fluence range satisfactorily. However, if one assumes a relation

$f_{\mathrm{i}}(\Phi)=f_{\mathrm{i} 0} \frac{1}{1+\left(\Phi / \Phi_{\mathrm{t}}\right)^{p}}$

i.e. that the $V_{\mathrm{Ga}}$ concentration $C$ depends on the power $\Phi^{p}$ of the implanted fluence, a good fit is obtained for $p=0.455$ [Figure $4(\mathrm{e})]$, which means an approximate square root dependency $C \sim \Phi^{1 / 2}$. In contrast, when Equation (3) is used to fit the fluence dependence in nid-GaN [Figure 4(b)] and $p-\mathrm{GaN}: \mathrm{Mg}$ [Figure 4(c)] at RT, one obtains exponents of $p=1.00$ and $p=0.896$, i.e. approximately a linear dependency. Thus, it seems, while at RT interstitial $\mathrm{Mg}_{\mathrm{i}}$ is depleted as if gallium vacancies accumulate proportional to the implanted fluence, at $300^{\circ} \mathrm{C}$ the decrease of $\mathrm{Mg}_{\mathrm{i}}$ is somewhat slower than expected from a proportional relation for $\Phi>\Phi_{\mathrm{t}}$ but faster for $\Phi<\Phi_{\mathrm{t}}$, with $\Phi_{\mathrm{t}}=3.4 \times 10^{12} \mathrm{~cm}^{-2}$.

e) At the implantation temperature of $400^{\circ} \mathrm{C}$ an entirely new trend sets in. The amount of interstitial ${ }^{27} \mathrm{Mg}$ is now either already considerably reduced at low fluences [ $n-\mathrm{GaN}: \mathrm{Si}$, Figure 2(a)] or drops very sharply as a function of fluence $[p-\mathrm{GaN}: \mathrm{Mg}$ and $\mathrm{GaN}: \mathrm{Mg}$ as grown, Figure 2(c) and 2(d)]. Further increases in the implantation temperature progressively decrease the amount of interstitial Mg. Note that in Figure 2(c) the interstitial fractions measured at $500^{\circ} \mathrm{C}$ and $600^{\circ} \mathrm{C}$ start at similar values around $\sim 9 \%$. While at $500^{\circ} \mathrm{C}$ a drop to $4-$ $5 \%$ is visible once more than $\sim 5 \times 10^{6}$ events have accumulated on this beam spot, for $600^{\circ} \mathrm{C}$ no data is available for this number of events; however, it is clear from Figure 5(c) that for prolonged implantations also $4-5 \%$ are reached at this temperature. Presently, at $800^{\circ} \mathrm{C}$ interstitial $\mathrm{Mg}$ reaches values that are a few per cent only or practically $0 \%$ [Figure 2(c) and 5]. As we have previously outlined in Ref. ${ }^{[31]}$, this can be explained by the onset of the interstitial migration of ${ }^{27} \mathrm{Mg}_{\mathrm{i}}$, which leads to its diffusion in the sample until it finds a $\mathrm{Ga}$ vacancy $V_{\text {Ga }}$ with which it can combine and thus be incorporated on substitutional Ga sites. This process was studied in more detail for all four doping types of GaN, by means of 


\section{WILEY-VCH}

determining the relative interstitial fraction of ${ }^{27} \mathrm{Mg}_{\mathrm{i}}$ as a function of implantation

temperature, without changing the beam spot and integrating over larger numbers of events, so that oscillations and fast, initial relaxations are averaged out. The results are displayed in Figure 5. The major drops in the interstitial fractions all occur around $400^{\circ} \mathrm{C}$ and initially follow in considerable detail what is expected from thermally activated Arrhenius behaviour, as shall be outlined in the following. The relative interstitial fractions have been fitted using two models that were described in more detail in Refs. ${ }^{[31,34]}$. Assuming that a certain number of jumps $N$ is needed for ${ }^{27} \mathrm{Mg}_{\mathrm{i}}$ to encounter a Ga vacancy $V_{\mathrm{Ga}}$, the fraction $f_{\mathrm{i}}(T)$ that is still decaying on interstitial sites as a function of temperature $T$ should be given by

$f_{\mathrm{i}}(T)=f_{\mathrm{i} 0} \frac{1}{1+\frac{v_{0} \tau}{N} e^{\frac{-E_{\mathrm{M}}}{k_{\mathrm{B}} T}}}$

where $f_{\mathrm{i} 0}$ is the interstitial fraction at low temperatures, $w_{0}$ the jump attempt frequency, $\tau=818 \mathrm{~s}$ the radioactive lifetime of ${ }^{27} \mathrm{Mg}$, and $E_{\mathrm{M}}$ the activation energy for migration of interstitial ${ }^{27} \mathrm{Mg}_{\mathrm{i}}$. Note that this equation leads to a single, rather sharp drop in the interstitial fractions with the limit $f_{\text {ioo }}=0$ at high temperatures. Taking the attempt frequency $v_{0}=2 \times 10^{13} \mathrm{~Hz},{ }^{[31]} N$ was assumed either to be $1\left(V_{\mathrm{Ga}}\right.$ immediately neighboring $\left.{ }^{27} \mathrm{Mg}_{\mathrm{i}}\right)$, or $10^{5}$ (upper limit when the diffusion-induced broadening of the ${ }^{27} \mathrm{Mg}$ profile would become comparable to the implantation depth) and least square fits performed on the data sets in Figure 5. As it turned out, Equation (4) would generally not fit well the entire temperature regime from $300-800^{\circ} \mathrm{C}$, since it appears that there is still a second drop or slow decrease in $f_{\mathrm{i}}$ between $600-800^{\circ} \mathrm{C}$ in the nid-GaN and $\mathrm{Mg}$-doped samples. Such a behavior can be understood as resulting from a mechanism that slows down the migration for part of the interstitial ${ }^{27} \mathrm{Mg}$, such as being bound to other defects, so that for some ${ }^{27} \mathrm{Mg}_{\mathrm{i}}$ interstitials a higher activation energy is required to combine with Ga vacancies. Another factor that is not taken into account by Equation (4) is that, for higher implantation temperatures, the number of jumps $N$ that is needed should increase since the number of Ga vacancies is reduced. Thus, 


\section{WILEY-VCH}

while Equation (4) is likely to represent an over-simplification, when a constant term $f_{\text {io }}$ is added it fits very well the initial stages of the drop in the temperature range $300-600^{\circ} \mathrm{C}$ in all samples. The resulting best fit curves and migration energies have been included in Figure 5 . As can be seen, there are only small differences in the best fit values for $E_{\mathrm{M}}$ for the various samples, being around $2.17-2.31 \mathrm{eV}$ for $N=1$, and $1.50-1.59 \mathrm{eV}$ for $N=10^{5}$. While this indicates similar migration behavior in all four types of samples, it should be kept in mind that, as was already argued above, the Fermi level in all sample types probably was around mid-gap due to the sustained implantation damage in these prolonged measurements. Hence one may not conclude that the migration behavior of $\mathrm{Mg}$ is the same irrespective of the Fermi level of the sample. Our estimate for $E_{\mathrm{M}}$ falls close to the range of values $E_{\mathrm{M} \|}=2.01 \mathrm{eV}$ and $E_{\mathrm{M} \perp}=2.20 \mathrm{eV}$ recently predicted by theory ${ }^{[32]}$ for migration of interstitial $\mathrm{Mg}_{\mathrm{i}}{ }^{2+}$ in $\mathrm{GaN}$ parallel and perpendicular to the $c$-axis, respectively. As we have previously outlined, ${ }^{[33]}$ activation energies for interstitial migration $E_{\mathrm{M}}$ estimated from emission channeling experiments of ${ }^{8} \mathrm{Li},{ }^{11} \mathrm{Be},{ }^{24} \mathrm{Na}$ and ${ }^{27} \mathrm{Mg}$ in $\mathrm{GaN}$ and ${ }^{24} \mathrm{Na}$ and ${ }^{27} \mathrm{Mg}$ in $\mathrm{AlN}$ were found to be correlated with the ionic radii of $\mathrm{Li}^{+}, \mathrm{Be}^{2+}, \mathrm{Na}^{+}$, and $\mathrm{Mg}^{2+}$ and in agreement with most theoretical predictions. The data presented here further confirm this finding. We would like to point out that by means of stable ${ }^{26} \mathrm{Mg}$ implantations the amount of implanted $\mathrm{Mg}$ in the peak of the implantation profile reached values that exceeded several times the doping level of $2 \times 10^{19} \mathrm{~cm}^{-3}$ of $\mathrm{Mg}$ incorporated during growth of the GaN:Mg samples. We also note that the background-corrected sum fractions $f_{\mathrm{i}}+f_{\mathrm{S}}$ of interstitial and substitutional ${ }^{27} \mathrm{Mg}$ stayed rather constant around $100 \%$ up to the highest implantation fluences used in the experiments, cf. Supporting Information. This means that only small amounts of ${ }^{27} \mathrm{Mg}$ were incorporated in irregular lattice sites, as would, e.g., be expected to occur during Mg clustering. Hence, by means of ion implantation it seems straightforward to 
introduce the overwhelming amount of $\mathrm{Mg}(>95 \%)$ into substitutional Ga sites even at doping levels of $5 \times 10^{19} \mathrm{~cm}^{-3}$.

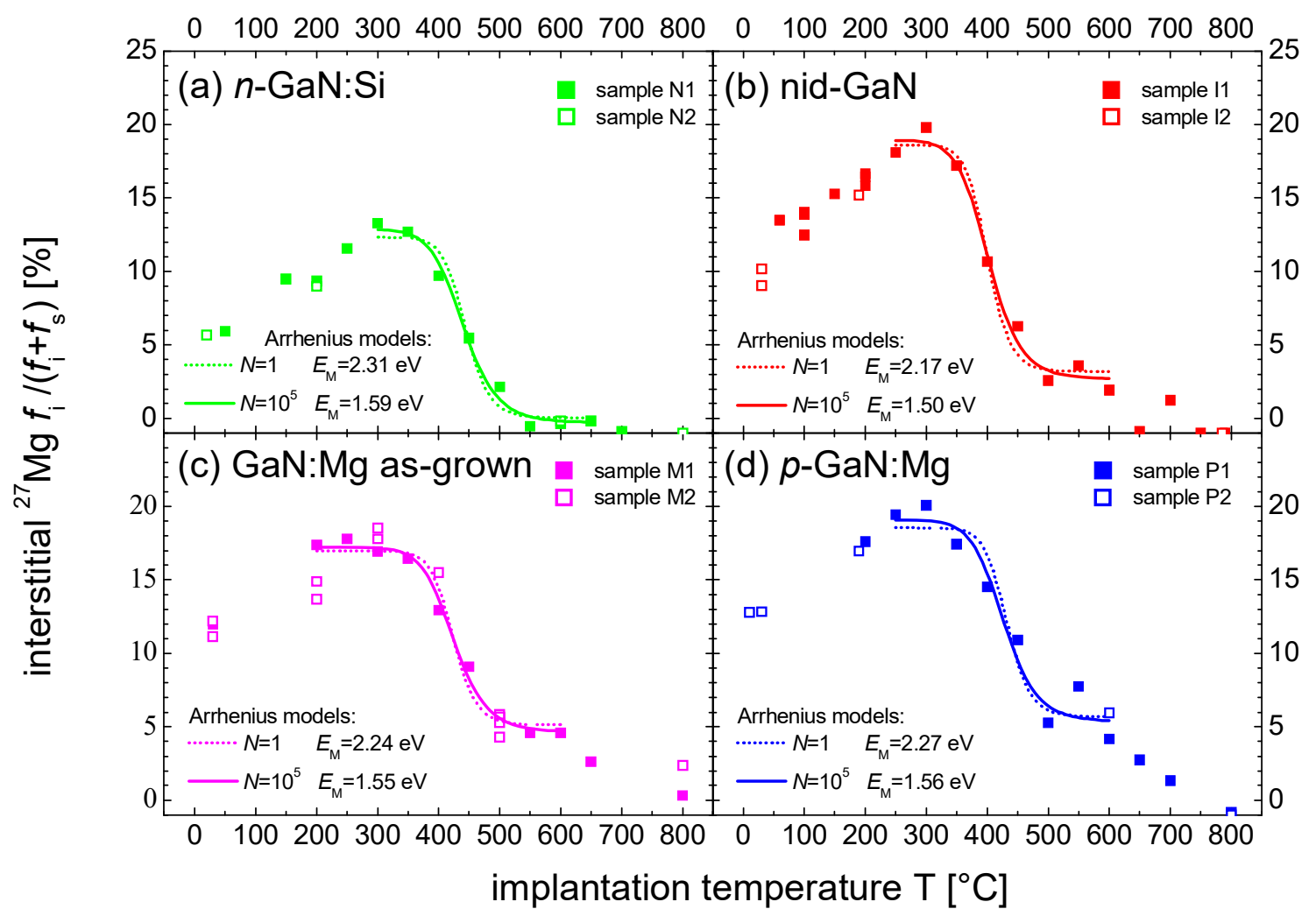

Figure 5. Relative amount of interstitial ${ }^{27} \mathrm{Mg}$ as a function of implantation temperature in the four doping types of $\mathrm{GaN}$ investigated. Note that each panel includes results from two different samples, whose internal nomenclature is shown in the panels. For these measurements the beam spots on the samples were left unchanged, along with longer measuring times at each temperature, i.e. initial transients related to Fermi level changes in the samples and fluctuations, such as are observed in Figure 2(a)-2(d) are averaged out. The number of events accumulated at the end of the temperature sequences for samples N1, I1, M1 and P1 was (a) $3.5 \times 10^{7}$, (b) $3.0 \times 10^{7}$, (c) $4.5 \times 10^{7}$, (d) $2.3 \times 10^{7}$. The dotted and solid lines represent fits of two Arrhenius models for the site changes of interstitial ${ }^{27} \mathrm{Mg}$ to substitutional positions, as is described in more detail in the text, performed for the temperature range around $400^{\circ} \mathrm{C}$ where the most prominent steps occur. The number of jumps $N$ of $\mathrm{Mg}_{\mathrm{i}}$ 


\section{WILEY-VCH}

considered in the models is either $N=1$ or $N=10^{5}$, while $E_{\mathrm{M}}$ is the corresponding best fit value for the interstitial migration energy.

\section{Conclusion}

We identified three key parameters that regulate the incorporation of implanted $\mathrm{Mg}$, i.e. the balance between substitutional Ga and interstitial site occupancy: $i$ ) the position of the Fermi level, ii) the amount of Ga vacancies available during implantation, and, iii) at temperatures of $400^{\circ} \mathrm{C}$ and above, the ability of $\mathrm{Mg}_{\mathrm{i}}$ to migrate and combine with $\mathrm{Ga}$ vacancies.

i) The Fermi-level dependence of the formation of interstitial vs substitutional $\mathrm{Mg}$ means that the amount of interstitial $\mathrm{Mg}$ formed is highest when the Fermi level is low in the band gap, i.e. in $p$-type material. However, with increasing fluence the implantation-related defects push the Fermi level towards the middle of the band gap, as schematically illustrated in Figure 3, which reduces the amount of interstitial $\mathrm{Mg}_{\mathrm{i}}$ to levels which are similar to undoped material. The fact that this also happens in samples that were Mg-doped during growth but not activated through post-growth thermal annealing, indicates that these were actually also $p$ type, however, with lower hole concentration since the fluence effect was faster. We also have strong indications that the amount of interstitial $\mathrm{Mg}_{\mathrm{i}}$ is influenced by changes in the Fermi level close to the surface due to positive charges building up near the GaN surface during implantation.

ii) The observation that the amount of interstitial $\mathrm{Mg}_{\mathrm{i}}$ initially increases with implantation temperature $T_{\mathrm{i}}$ (up to $T_{\mathrm{i}}=400^{\circ} \mathrm{C}$ ) can be explained by the fact that implantation at elevated temperatures creates less Ga vacancies, which hinders the substitutional incorporation of $\mathrm{Mg}$. A second mechanism at work in $p$-type samples, is the overall reduction of defects so that damage-related shifts of the Fermi level are less pronounced and the $p$-type character preserved up to higher fluences. 


\section{WILEY-VCH}

iii) Finally, implanting at temperatures at $400^{\circ} \mathrm{C}$ and above progressively converts interstitial

${ }^{27} \mathrm{Mg}_{\mathrm{i}}$ to substitutional Ga sites in all doping types. This is due to the onset of the migration of interstitial $\mathrm{Mg}_{\mathrm{i}}$ at this temperature, which leads to its capture on substitutional Ga sites when encountering Ga vacancies. The detailed temperature dependence of this process was interpreted based on Arrhenius models, from which for all four sample types the activation energy $E_{\mathrm{M}}$ for migration of interstitial $\mathrm{Mg}_{\mathrm{i}}$ was estimated between $1.5 \mathrm{eV}$ and $2.3 \mathrm{eV}$.

Independent of doping type, the amount of interstitial ${ }^{27} \mathrm{Mg}_{\mathrm{i}}$ found in samples implanted close to RT or $300{ }^{\circ} \mathrm{C}$ with the stable isotopes ${ }^{24} \mathrm{Mg},{ }^{25} \mathrm{Mg}$ or ${ }^{26} \mathrm{Mg}$ at fluences above $10^{14} \mathrm{~cm}^{-2}$ (the technologically relevant fluence range) is at maximum at the level of several per cent. In particular this means that the amount of stable Mg introduced during previous implantations or from doping during growth $\left(2 \times 10^{19} \mathrm{~cm}^{-3}\right)$ does not lead to a significant increase of the interstitial fraction for implanted ${ }^{27} \mathrm{Mg}$ or to $\mathrm{Mg}$ clustering at the fluences investigated here. This underscores that, at technologically relevant fluences, ion implantation is a very efficient means of introducing $\mathrm{Mg}$ into substitutional Ga sites. It also illustrates that the problems of electrical activation faced for implanted $\mathrm{Mg}$ are not related to the lack of substitutional incorporation but rather to the compensating role of implantation defects. Removing the latter through annealing at temperatures well above $900^{\circ} \mathrm{C}$ (a temperature regime not accessible to our experimental setup) can, however, lead to long-range Mg diffusion and clustering.

\section{Experimental Section}

Details on the production of the radioactive isotope ${ }^{27} \mathrm{Mg}$ at CERN's ISOLDE on-line isotope separator facility, ${ }^{[47]}$ the experimental conditions, the theoretical simulation of $\beta^{-}$emission patterns, and the data analysis procedure have been given in our previous paper ${ }^{[31]}$ and its supplemental material. For detection of angular-dependent $\beta^{-}$emission yields we used a $3 \times 3 \mathrm{~cm}^{2}$ position-sensitive Si pad detector with $22 \times 22$ pixels ${ }^{[37]}$ placed at $30 \mathrm{~cm}$ from the sample, resulting in an angular resolution of $0.1^{\circ}$. 
WILEY-VCH

Most of the measurements were performed with $50 \mathrm{keV}$ implantations of ${ }^{27} \mathrm{Mg}^{+}$into a $1 \mathrm{~mm}$ diameter beam spot under an angle of $17^{\circ}$ from the surface normal of the samples, using the on-line setup described in Ref. ${ }^{[48]}$, which allows simultaneous implantation and measurement. For some measurements the implantation energy was lowered to $20 \mathrm{keV}$ in order to maximize the ${ }^{27} \mathrm{Mg}$ peak concentration and introduce the implanted atoms closer to the surface. The ${ }^{27} \mathrm{Mg}$ profiles resulting from $50 \mathrm{keV}$ implantation are approximately Gaussian with mean depth and straggling of $488 \pm 244 \AA$, the ones from $20 \mathrm{keV}$ yield $205 \pm 107 \AA$. The beam currents of ${ }^{27} \mathrm{Mg}^{+}$into the $1 \mathrm{~mm}$ diameter beam spot ranged from $0.06 \mathrm{pA}$ to $0.8 \mathrm{pA}$ (corresponding to $3.8 \times 10^{5}-5 \times 10^{6}$ atoms s $\mathrm{s}^{-1}$ ).

Implanting the radioactive ion beam of ${ }^{27} \mathrm{Mg}$ with sub-pA currents (fluence rates 0.5$6.3 \times 10^{8} \mathrm{~cm}^{-2} \mathrm{~s}^{-1}$ ) allowed to reach a maximum implantation fluence regime around 4$5 \times 10^{12} \mathrm{~cm}^{-2}$, corresponding to $2.5-3.1 \times 10^{7}$ events on a single beam spot. In order to explore the fluence regime around $10^{14} \mathrm{~cm}^{-2}$, which is relevant for technological applications, we used the fact that ISOLDE is also able to deliver beams of the stable isotopes ${ }^{24} \mathrm{Mg},{ }^{25} \mathrm{Mg}$ and ${ }^{26} \mathrm{Mg}$ at considerably higher currents than ${ }^{27} \mathrm{Mg}$. While the stable implantations were performed under the same conditions as using the radioactive ion beam, the currents ranged from $36 \mathrm{pA}$ to $168 \mathrm{pA}$, corresponding to $0.6-2.9 \times 10^{10} \mathrm{~cm}^{-2} \mathrm{~s}^{-1}$. Following each stable implantation, the samples were implanted with radioactive ${ }^{27} \mathrm{Mg}$ in order to probe the changes in lattice site prevalence of ${ }^{27} \mathrm{Mg}$ caused by the increase in implanted $\mathrm{Mg}$ fluence.

\section{Supporting Information}

Supporting Information is available from the Wiley Online Library or from the author.

\section{Acknowledgements}

We acknowledge the support of the ISOLDE Collaboration and technical teams. This work was funded by the Portuguese Foundation for Science and Technology (FCT, CERN/FISPAR/0005/2017), the Research Foundation-Flanders (FWO), and the KU Leuven (BOF 
program). The EU Horizon 2020 Framework supported ISOLDE beam times through grant agreement 654002 (ENSAR2) and use of KU Leuven facilities through 824096 (RADIATE). G.L. and T.A.L.L. acknowledge the support by FWO (Projects No. 27531, 52751, 29681 and 52152).

Received: ((will be filled in by the editorial staff))

Revised: ((will be filled in by the editorial staff)) Published online: ((will be filled in by the editorial staff))

\section{References}

[1] J. Baliga, Semicond. Sci. Technol. 2013, 28, 074011.

[2] M. J Scott, L. Fu, X. Zhang, J. Li, C. Yao, M. Sievers, J. Wang, Semicond. Sci. Technol. 2013, 28, 074013.

[3] H. Amano, Y. Baines, E. Beam, M. Borga, T. Bouchet, P. R Chalker, M. Charles, K. J. Chen, N. Chowdhury, R. Chu, C. De Santi, M. M. De Souza, S. Decoutere, L. Di Cioccio, B. Eckardt, T. Egawa, P. Fay, J. J. Freedsman, L. Guido, O. Häberlen, G. Haynes, T. Heckel, D. Hemakumara, P. Houston, J. Hu, M. Hua, Q. Huang, A. Huang, S. Jiang, H. Kawai, D. Kinzer, M. Kuball, A. Kumar, K. B. Lee, X. Li, D. Marcon, M. März, R. McCarthy, G. Meneghesso, M. Meneghini, E. Morvan, A. Nakajima, E. M. S. Narayanan, S. Oliver, T. Palacios, D. Piedra, M. Plissonnier, R. Reddy, M. Sun, I. Thayne, A. Torres, N. Trivellin, V. Unni, M. J. Uren, M. Van Hove, D. J Wallis, J. Wang, J. Xie, S. Yagi, S. Yang, C. Youtsey, R. Yu, E. Zanoni, S. Zeltner, Y. Zhang, J. Phys. D: Appl. Phys. 2018, 51, 163001.

[4] J. Hu, Y. Zhang, M. Sun, D. Piedra, N. Chowdhury, T.Palacios, Mater. Sci. Semicond. Process. 2018, 78, 75.

[5] J. Y. Tsao S. Chowdhury, M. A. Hollis, D. Jena, N. M. Johnson, K. A. Jones, R. J. Kaplar, S. Rajan, C. G. Van de Walle, E. Bellotti, C. L. Chua, R. Collazo, M. E. Coltrin, J. A. Cooper, K. R. Evans, S. Graham, T. A. Grotjohn, E. R. Heller, M. Higashiwaki, M. S. Islam, 


\section{WILEY-VCH}

P. W. Juodawlkis, M. A. Khan, A. D. Koehler, J. H. Leach, U. K. Mishra, R. J. Nemanich, R. C. N. Pilawa-Podgurski, J. B. Shealy, Z. Sitar, M. J. Tadjer, A. F. Witulski, M. Wraback, J. A. Simmons, Adv. Electron. Mater. 2018, 4, 1600501.

[6] J. He, W. C. Cheng, Q. Wang, K. Cheng, H. Yu, Y. Chai, Adv. Electron. Mater. 2021, 2001045.

[7] B. N. Pushpakaran, A. S. Subburaj, S. B. Bayne, J. Electronic Materials 2020, 49, 6247.

[8] T. Narita, H. Yoshida, K. Tomita, K. Kataoka, H. Sakurai, M. Horita, M. Bockowski, N. Ikarashi, J. Suda, T. Kachi, Y. Tokuda, J. Appl. Phys. 2020, 128, 090901.

[9] S. Brochen, J. Brault, S. Chenot, A. Dussaigne, M. Leroux, B. Damilano, Appl. Phys. Lett. 2013, 103, 032102.

[10] C. G. Van de Walle, J. Neugebauer, J. Appl. Phys. 2004, 95, 3851.

[11] F. A. Reboredo, S. T. Pantelides, Phys. Rev. Lett. 1999, 82, 1887.

[12] F. A. Reboredo, S. T. Pantelides, MRS Internet J. Nitride Semicond. Res. 1999, 4(S1), 508.

[13] G. Miceli, A. Pasquarello, Phys. Rev. B 2016, 93, 165207.

[14] L. Amichi, I. Mouton, E. Di Russo, V. Boureau, F. Barbier, A. Dussaigne, A. Grenier, P. H. Jouneau, C. Bougerol, D. Cooper, J. Appl. Phys. 2020, 127, 065702.

[15] J. I. Pankove, J. A. Hutchby, J. Appl. Phys. 1976, 47, 5387.

[16] J. C. Zolper, J. Cryst. Growth 1997, 178, 157.

[17] S. J. Pearton, J. C. Zolper, R. J. Shul, F. Ren, J. Appl. Phys. 1999, 86, 1.

[18] S. O. Kucheyev, J. S. Williams, S. J. Pearton, Mater. Sci. Eng. 2001, 33, 51.

[19] B. N. Feigelson, T. J. Anderson, M. Abraham, J. A. Freitas, J. K. Hite, C. R. Eddy, F. J. Kub, J. Cryst. Growth 2012, 350, 21.

[20] T. Niwa, T. Fujii, T. Oka, Appl. Phys. Express 2017, 10, 091002. 


\section{WILEY-VCH}

[21] V. Meyers, E. Rocco, T. J. Anderson, J. C. Gallagher, M. A. Ebrish, K. Jones, M.

Derenge, M. Shevelev, V. Sklyar, K. Hogan, B. McEwen, F. Shahedipour-Sandvik, J. Appl.

Phys. 2020, 128, 085701.

[22] M. Takahashi, A. Tanaka, Y. Ando, H. Watanabe, M. Deki, M. Kushimoto, S. Nitta,

Y. Honda, K. Shima, K. Kojima, S. F. Chichibu, H. Amano, Jpn. J. Appl. Phys. 2020, 59, 056502.

[23] H. Sakurai, M. Omori, S. Yamada, Y. Furukawa, H. Suzuki, T. Narita, K. Kataoka, M. Horita, M. Bockowski, J. Suda, T. Kachi, Appl. Phys. Lett. 2019, 115, 142104.

[24] T. Nakashima, E. Kano, K. Kataoka, S. Arai, H. Sakurai, T. Narita, K. Sierakowski, M. Bockowski, M. Nagao, J. Suda, T. Kachi, N. Ikarashi, Appl. Phys. Express 2021, 14, 011005.

[25] Y. T. Shi, F. F. Ren, J. Hao, Z. Wang, J. Ye, W. Z. Xu, D. Zhou, R. Zhang, Y. Zheng, H. Lu, J. Appl. Phys. 2020, 128, 235704.

[26] R. Tanaka, S. Takashima, K. Ueno, H. Matsuyama, M. Edo, Jpn. J. Appl. Phys. 2020, 59, SGGD02.

[27] M. Yoshino, Y. Ando, M. Deki, T. Toyabe, K. Kuriyama, Y. Honda, T. Nishimura, H. Amano, T. Kachi, T. Nakamura, Materials 2019, 12, 689.

[28] M. Yoshino, K. Sugamata, K. Ikeda, T. Nishimura, K. Kuriyama, T. Nakamura, Nucl. Instrum. Methods Phys. Res., Sect. B 2019, 449, 49.

[29] W. Xu, Y. Shi, F. Ren, D. Zhou, L. Su, Q. Liu, L. Cheng, J. Ye, D. Chen, R. Zhang, Y. Zheng, H. Lu, Photonics Res. 2019, 7, B48.

[30] Y. T. Shi, F. F. Ren, W. Z. Xu, X. Chen, J. Ye, L. Li, D. Zhou, R. Zhang, Y. Zheng, H. H. Tan, C. Jagadish, H. Lu, Sci. Rep. 2019, 9, 8796.

[31] U. Wahl, L. M. Amorim, V. Augustyns, A. Costa, E. David-Bosne, T. A. L. Lima, G. Lippertz, J. G. Correia, M. R. da Silva, M. J. Kappers, K. Temst, A. Vantomme, L. M. C. Pereira, Phys. Rev. Lett. 2017, 118, 095501. 


\section{WILEY-VCH}

[32] G. Miceli, A. Pasquarello, Phys. Status Solidi RRL 2017, 11, 1700081.

[33] U. Wahl, E. David-Bosne, L. M. Amorim, A. R. G. Costa, B. De Vries, J. G. Correia, M. R. da Silva, L. M. C. Pereira, A. Vantomme, J. Appl. Phys. 2020, 128, 045703.

[34] L. M. Amorim, U. Wahl, L. Pereira, S. Decoster, D. J. Silva, M. R. da Silva, A.

Gottberg, J. G. Correia, K. Temst, A. Vantomme, Appl. Phys. Lett. 2013, 103, 262102.

[35] H. Hofsäss, G. Lindner, Phys. Rep. 1991, 201, 121.

[36] U. Wahl, Hyperfine Interact. 2000, 129, 349.

[37] U. Wahl, J. G. Correia, A. Czermak, S. Jahn, P. Jalocha, J. Marques, A. Rudge, F.

Schopper, J. C. Soares, A. Vantomme, Nucl. Instrum. Methods Phys. Res., Sect. A 2004, 524, 245.

[38] L. M. C. Pereira, A. Vantomme, U. Wahl, in Characterisation and Control of Defects in Semiconductors, (Ed. F. Tuomisto), The Institution of Engineering and Technology, Stevenage, UK 2019, Ch. 11.

[39] E. David-Bosne, U. Wahl, J. G. Correia, T. A. L. Lima, A. Vantomme, L. M. C. Pereira, Nucl. Instrum. Methods Phys. Res., Sect. B 2020, 462, 102.

[40] F. Karouta, M. J. Kappers, M. C. J. C. M. Krämer, B. Jacobs, Electrochem. Solid-State Lett. 2005, 8, G170.

[41] S. Barbet, R. Aubry, M. A. di Forte-Poisson, J. C. Jacquet, D. Deresmes, T. Mélin, D. Théron, Appl. Phys. Lett. 2008, 93, 212107.

[42] Z. Huang, Y. Wu, Y. Zhao, L. Shi, R. Huang, F. Li, T. Liu, L. Xu, H. Gao, Y. Zhou, Q. Sun, S. Ding, K. Xu, H. Yang, AIP Advances 2019, 9, 115106.

[43] Y. Zhao, H. Gao, R. Huang, Z. Huang, F. Li, J. Feng, Q. Sun, A. Dingsun, H. Yang, Sci. Rep. 2019, 9, 16969.

[44] K. Pagowska, R. Ratajczak, A. Stonert, L. Nowicki, A. Turos, Vacuum 2009, 83, S145. 


\section{WILEY-VCH}

[45] E. Wendler, W. Wesch, A.Yu. Azarov, N. Catarino, A. Redondo-Cubero, E. Alves, K. Lorenz, Nucl. Instrum. Methods Phys. Res., Sect. B 2013, 307, 394.

[46] U. Wahl, Phys. Rep. 1997, 280, 145.

[47] R. Catherall, W. Andreazza, M. Breitenfeldt, A. Dorsival, G. J. Focker, T. P. Gharsa, T. J. Giles, J. L. Grenard, F. Locci, P. Martins, S. Marzari, J. Schipper, A. Shornikov, T. Stora, J. Phys. G 2017, 44, 094002.

[48] M. R. Silva, U. Wahl, J. G. Correia, L. M. Amorim, L. M. C. Pereira, Rev. Sci. Instrum. 2013, 84, 073506. 


\section{WILEY-VCH}

\section{Table of contents entry}

U. Wahl,* J. G. Correia, A. R. G. Costa, E. David-Bosne, M. J. Kappers, M. R. da Silva, G. Lippertz, T. A. L. Lima, R. Villarreal, A. Vantomme, and L. M. C. Pereira

Lattice Location Studies of the Amphoteric Nature of Implanted Mg in GaN

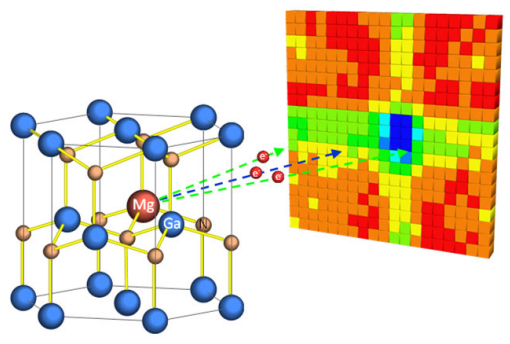

The lattice location of ${ }^{27} \mathrm{Mg}$ in different doping types of $\mathrm{GaN}$ is investigated as a detailed function of implantation temperature up to $800^{\circ} \mathrm{C}$ and fluence up to $>10^{14} \mathrm{~cm}^{-2}$. We elucidate the amphoteric nature of $\mathrm{Mg}$, i.e. the concurrent occupation of substitutional $\mathrm{Ga}$ and interstitial sites, which is being interpreted within the framework of a Fermi-level model. 


\section{Supporting Information}

\section{Lattice Location Studies of the Amphoteric Nature of Implanted Mg in GaN}

U. Wahl, * J. G. Correia, A. R. G. Costa, E. David-Bosne, M. J. Kappers, M. R. da Silva, G. Lippertz, T. A. L. Lima, R. Villarreal, A. Vantomme, and L. M. C. Pereira

\section{Position of interstitial $\mathrm{Mg}_{\mathrm{i}}$ in the $\mathrm{GaN}$ wurtzite lattice}

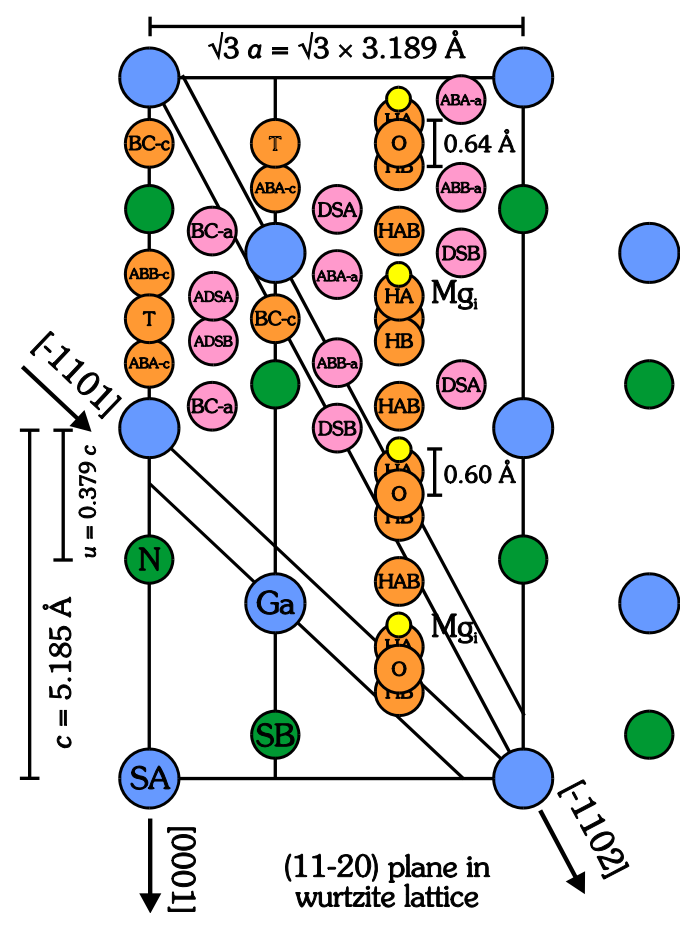

Figure S1. (11-20) plane in the GaN wurtzite lattice, showing the Ga (SA) and $\mathrm{N}(\mathrm{SB})$ atom positions and the major interstitial sites. The octahedral sites $\mathrm{O}$ are located in the wide-open interstitial region parallel to the [0001] axis and exactly centered in between planes of Ga and $\mathrm{N}$ atoms, as are the "hexagonal" $\mathrm{HAB}$ sites, while $\mathrm{HA}$ and $\mathrm{HB}$ are interstitial positions that have as closest neighbors A or B atoms. The best fit result from Ref. [31] for the position of interstitial $\mathrm{Mg}_{\mathrm{i}}$ is indicated by the yellow circles. It is shifted by $(-0.60 \pm 0.14) \AA$ from the ideal octahedral $\mathrm{O}$ position via the HA towards the HAB sites. 


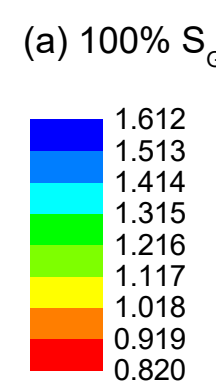

[0001]
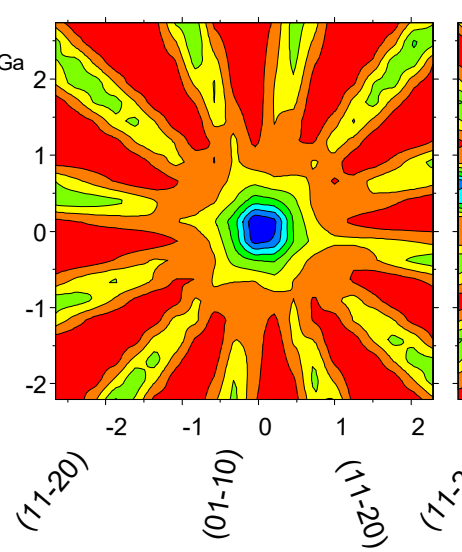

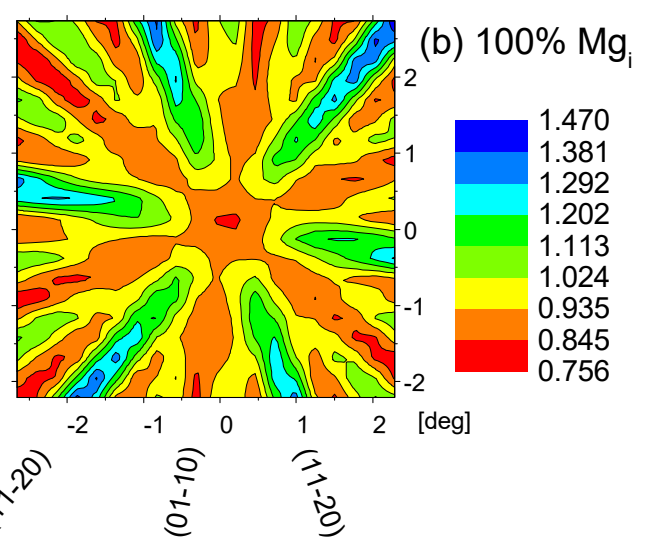

Figure S2. Theoretical $\beta^{-}$emission channeling patterns for $100 \%$ of ${ }^{27} \mathrm{Mg}$ emitter atoms on (a) substitutional $\mathrm{Ga}\left(\mathrm{S}_{\mathrm{Ga}}\right)$ and (b) interstitial sites parallel to the $c$-axis. The "many beam" simulations used to calculate the angular-dependent $\beta^{-}$emission yields assumed a Gaussian depth distribution of ${ }^{27} \mathrm{Mg}$ emitter atoms at $488 \pm 244 \AA$, as resulting from $50 \mathrm{keV}$ implantation. The orientation and angular resolution of the patterns are the same as those of the experimental pattern shown in Figure 1(c) of the main paper. Note that, while the [0001] axis and all major planes show channeling effects for $\mathrm{S}_{\mathrm{Ga}}$ occupation, for the $\mathrm{Mg}_{\mathrm{i}}$ sites the [0001] axis and (0110) planes exhibit blocking effects, leading to minima of the electron count rates along these directions. 


\section{Interstitial ${ }^{27} \mathrm{Mg}$ fractions for additional samples as a function of recorded detector} events
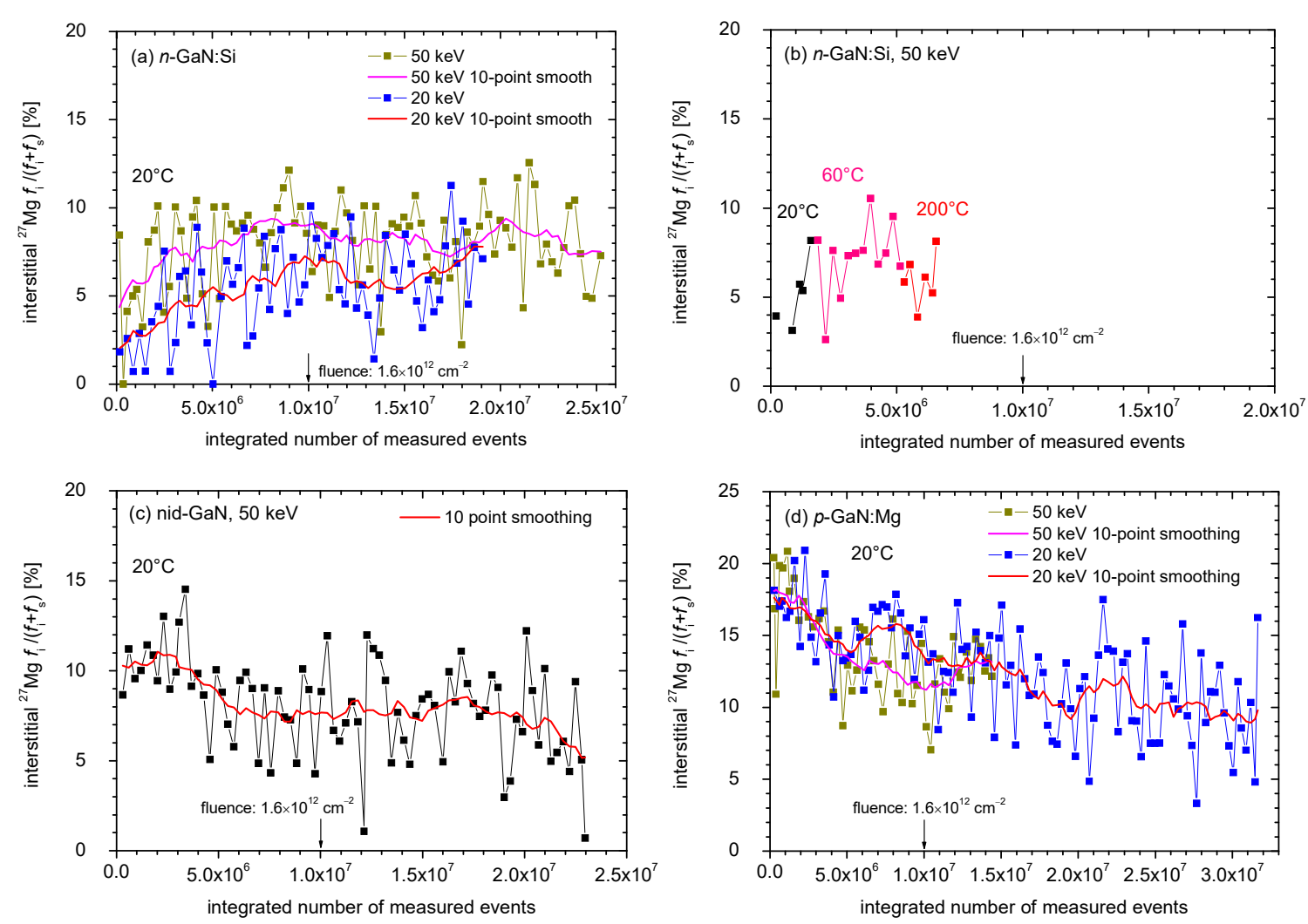

Figure S3. Relative amount of interstitial ${ }^{27} \mathrm{Mg}$ as a function of the integrated number of measured events for additional samples of (a)-(b) $n-\mathrm{GaN}: \mathrm{Si}$, (c) nid-GaN, and (d) $p$-GaN:Mg. The red and magenta curves in panels (a), (c) and (d) are 10-point smooths of the original data, thus eliminating short-time fluctuations due to surface charges. Panels (a) and (d) compare data from measurements for $20 \mathrm{keV}$ implantation to those for $50 \mathrm{keV}$ shown already in Figure 2(a) and 2(d) of the main paper. Panel (b) is an additional example for low interstitial fractions in $n$ $\mathrm{GaN}$ :Si. Note that for each implantation temperature shown in this panel a fresh beam spot was chosen. Thus, while every $1 \times 10^{7}$ events correspond to an implanted ${ }^{27} \mathrm{Mg}$ fluence of $1.6 \times 10^{12} \mathrm{~cm}^{-2}$, as indicated by the black arrows, the overall number of implanted $\mathrm{Mg}$ atoms did not accumulate in a single spot on the sample. Panel (c) is an additional example for intermediate interstitial fractions in nid-GaN, illustrating the fluctuations due to surface charges, and also the fluence dependence of $\mathrm{Mg}_{\mathrm{i}}$, which decreased from $10 \%$ at the beginning to $5-6 \%$ at $2.3 \times 10^{7}$ events (corresponding fluence $3.7 \times 10^{12} \mathrm{~cm}^{-2}$ ), similar to what is shown in Figure 2(b) and 4(b) of the main paper. 


\section{Interstitial ${ }^{27} \mathrm{Mg}$ fractions for an additional nid-GaN sample as a function of $\mathrm{Mg}$ fluence}

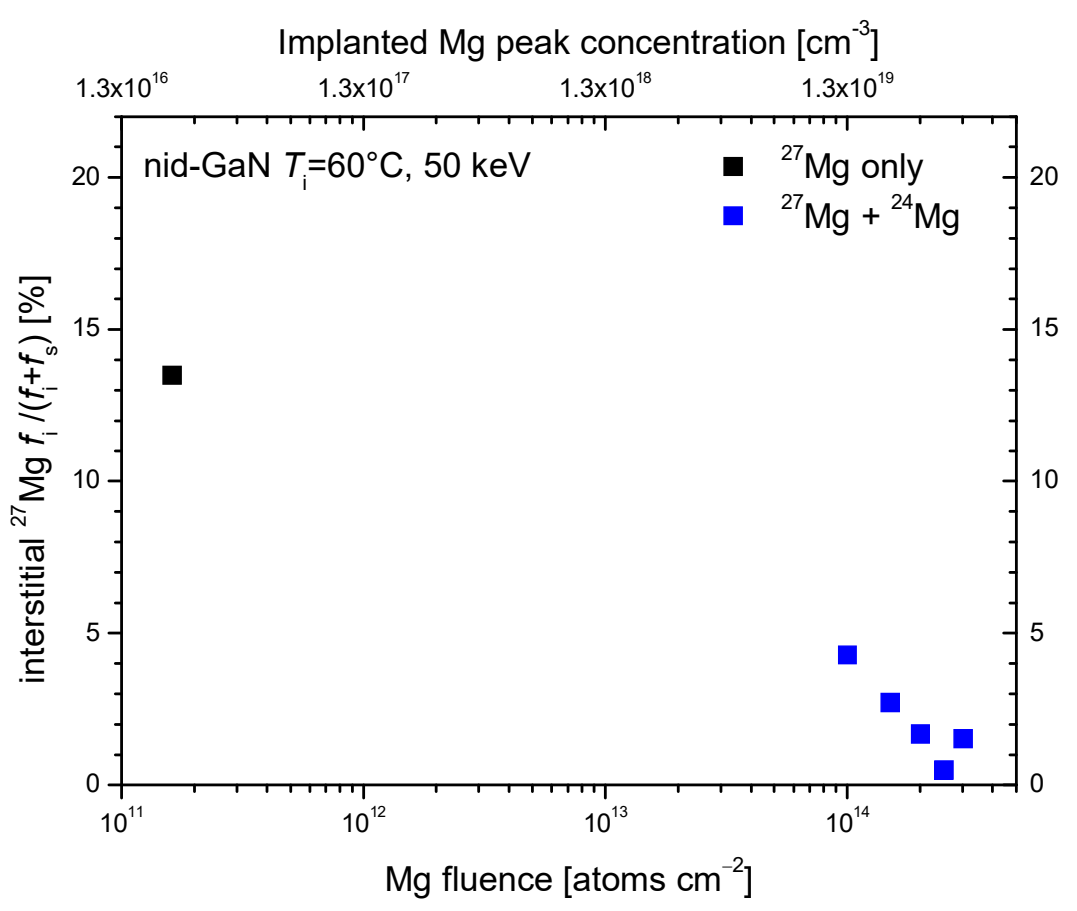

Figure S4. Relative amount of interstitial ${ }^{27} \mathrm{Mg}$ as a function of $\mathrm{Mg}$ fluence in an additional nid-GaN sample for $50 \mathrm{keV}$ implantation at $60^{\circ} \mathrm{C}$, cf. those shown in Figure 4 of the main paper. The black data point corresponds to implantation of radioactive ${ }^{27} \mathrm{Mg}$ only, while the ones in blue are following additional implantation steps of the stable isotope ${ }^{24} \mathrm{Mg}$. Note the logarithmic scale for the $\mathrm{Mg}$ fluence. The concentration of implanted $\mathrm{Mg}$ in the peak of the implantation profile is indicated at the top axis of the figure. 


\section{Capture model and logarithmic fits to fluence dependence of interstitial $\mathrm{Mg}$ in p-GaN:Mg}

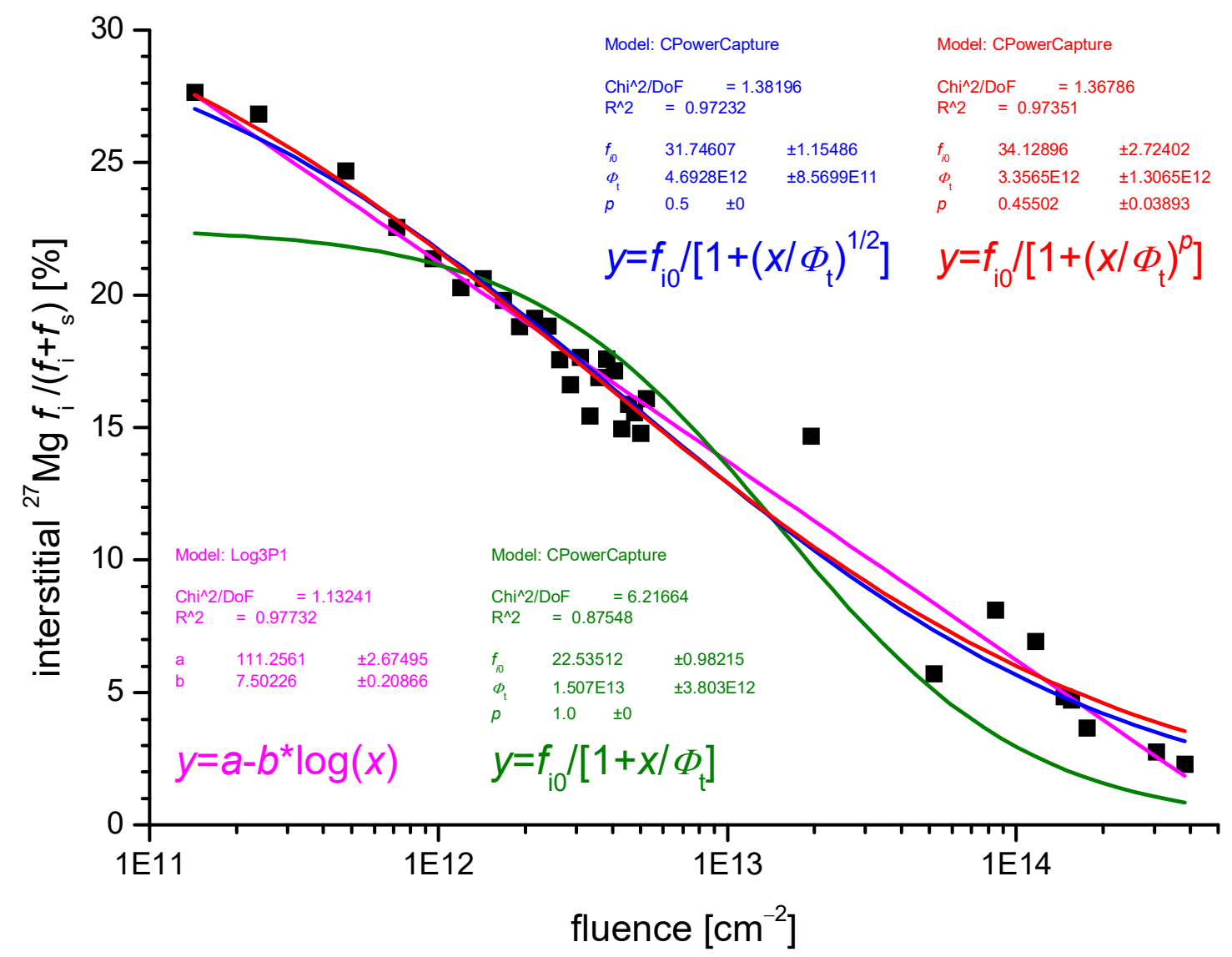

Figure S5. Relative amounts of interstitial ${ }^{27} \mathrm{Mg}$ as a function of $\mathrm{Mg}$ fluence in $p$-GaN:Mg for $50 \mathrm{keV}$ implantation at $300^{\circ} \mathrm{C}$ [same data as shown in Figure 4(e) of the main paper], together with the best fit of capture models of the functional form $y=f_{i 0} /\left[1+\left(x / \Phi_{\mathrm{t}}\right)^{p}\right]$ given in Equation (3) of the main paper. The simple capture model $y=f_{i 0} /\left[1+x / \Phi_{t}\right]$, which assumes that the concentration of $\mathrm{Ga}$ vacancies in the sample is proportional to the implanted $\mathrm{Mg}$ fluence, i.e. $p=1$, cannot be used to fit the entire fluence range satisfactorily. Allowing the exponent $p$ to vary, the best fit for $y=f_{i 0} /\left[1+\left(x / \Phi_{t}\right)^{p}\right]$ is obtained with the exponent $p=0.455$, i.e. very close to $1 / 2$. The best fit of the capture model depending on the square root of fluence $y=f_{i 0} /\left[1+\left(x / \Phi_{t}\right)^{1 / 2}\right]$, i.e. $p=1 / 2$, yields a very similar fit quality. Also shown is the fit of a logarithmic dependence of the form $y=a-b \log (x)$, which provides also a surprisingly good fit quality for $a=111 \%$ and $b=7.50 \%$, i.e. with the interstitial fraction decreasing by $7.5 \%$ for each decade of fluence in the considered range. 


\section{Background corrected sum fractions $f_{\mathrm{i}}+f_{\mathrm{S}}$ of ${ }^{27} \mathrm{Mg}$ as a function of Mg fluence}

Measurements of electron emission channeling effects are always subject to background which arises from two sources. First there is the contribution from electrons that are backscattered from inside the sample or from the walls of the vacuum chamber. This effect can only be theoretically estimated, in our case by performing GEANT4 Monte Carlo simulations of electron trajectories.

The second contribution arises from the background of gammas that are either emitted by the sample itself, by radioisotopes in the vicinity, or which result from cosmic radiation. The gamma background can be experimentally estimated by closing a shutter valve in front of the detector, which stops all electrons from the sample but allows most of the $\gamma$ particles to pass. While routinely performed at intervals during the experiments, this procedure does not allow to continuously monitor the background. The gamma background in off-line experiments with long-lived radioisotopes is generally rather stable with time, however, in on-line experiments with short-lived isotopes such as ${ }^{27} \mathrm{Mg}$ it is subject to fluctuations. These arise basically from two sources. First of all, the collimation of the ISOLDE beam to $1 \mathrm{~mm}$ diameter by means of a nozzle results in only about $50 \%$ of the ${ }^{27} \mathrm{Mg}$ beam being implanted into the sample. The rest is deposited inside the collimating nozzle, which is located about $25 \mathrm{~cm}$ from the sample (cf. Ref. [Silva 13] for a sketch of the experimental setup). The gamma radiation emitted by the ${ }^{27} \mathrm{Mg}$ isotopes deposited in the nozzle, while shielded from direct line of sight towards the detector, partially passes through the shielding and thus also contributes to the detector count rate. If the focusing of the ion beam changes, so do the relative fractions of ions implanted into the sample and deposited inside the collimating nozzle, which somewhat changes the signal to background ratio. The second but less important source is the overall gamma background in the ISOLDE experimental hall, which is subject to fluctuations e.g. due to variations of the intensity of the proton beam that induces a multitude of nuclear reactions inside the radioisotope production target. In experiments with short-lived isotopes such as ${ }^{27} \mathrm{Mg}$, gamma background from cosmic radiation is usually negligible in comparison to the high electron count rate from the sample. In general, overall fluctuations in gamma background during on-line experiments with ${ }^{27} \mathrm{Mg}$ amount to around $\pm 5-10 \%$, and thus lead to similar fluctuations in the estimated sum fractions $f_{\mathrm{i}}+f_{\mathrm{S}}$.

The sum fractions $f_{\mathrm{i}}+f_{\mathrm{S}}$ for various experiments, shown in Figure S6, were found to be somewhat higher than $100 \%$. This indicates that the background that is contributed by scattered electrons and that was simulated by means of GEANT4, has been overestimated to some extent (the expected accuracy of the scattered electron background simulations of the order of $\pm 10 \%$ ). As can be seen from the figure, the sum fractions show the tendency to decrease by a few per cent up to the highest fluences. This can be attributed to a few per cent of ${ }^{27} \mathrm{Mg}$ being incorporated in irregular lattice sites, such as in clusters, but can also be a consequence of damage accumulated in the GaN crystal. Both effects cause a decrease in the anisotropy of electron channeling effects, with a corresponding decrease in the fitted sum fractions $f_{\mathrm{i}}+f_{\mathrm{S}}$, and an increase in the so/called "random fraction", which is characterized by a flat contribution to the electron emission channeling patterns. 
WILEY-VCH
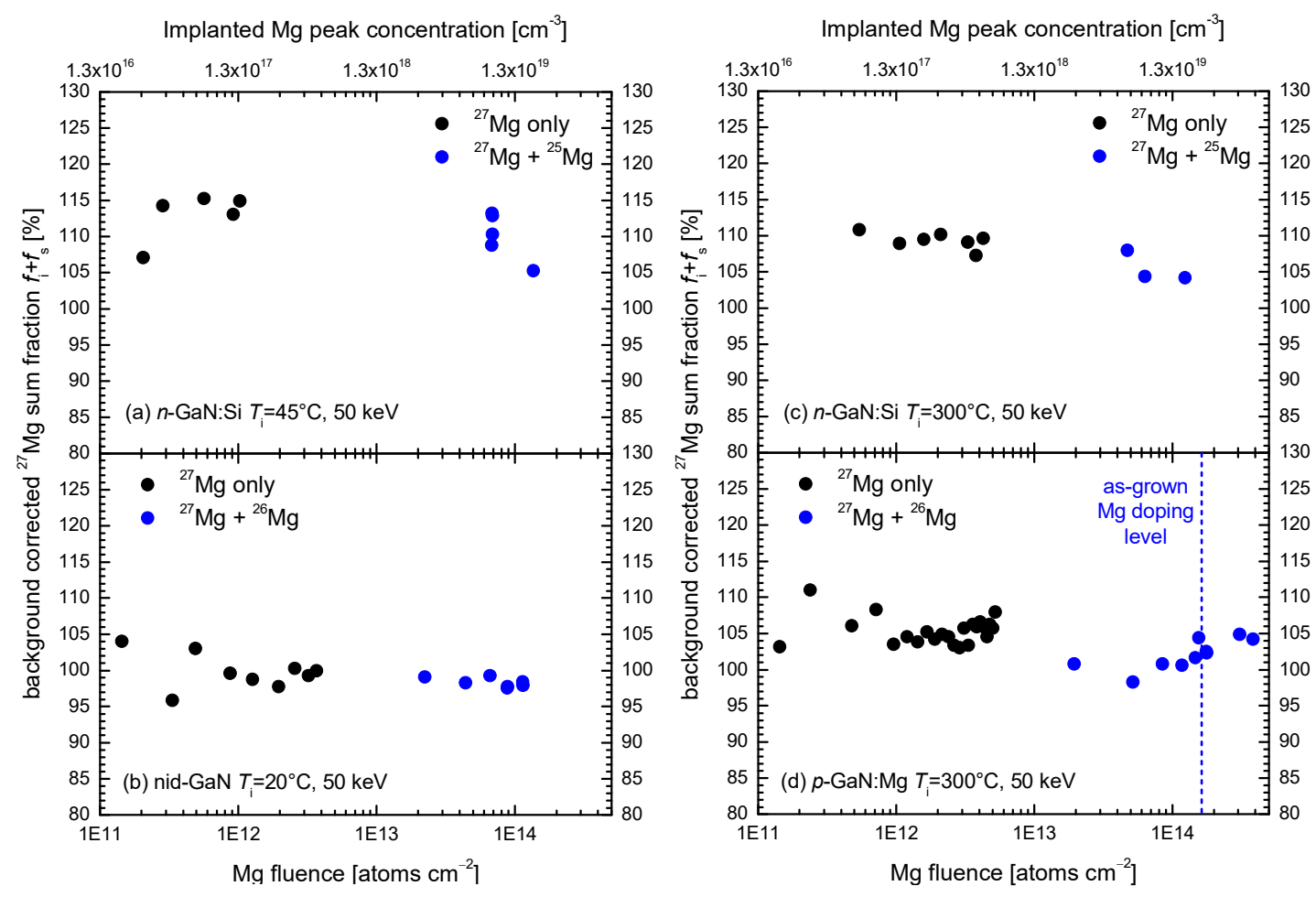

Figure S6. Background corrected sum fractions $f_{\mathrm{i}}+f_{\mathrm{S}}$ of ${ }^{27} \mathrm{Mg}$ as a function of $\mathrm{Mg}$ fluence in (a) $n$-GaN:Si and (b) nid-GaN for implantations close to RT, and in (c) $n$-GaN:Si and (d) $p$ $\mathrm{GaN}: \mathrm{Mg}$ for implantations at $300^{\circ} \mathrm{C}$. The black data points correspond to implantation of radioactive ${ }^{27} \mathrm{Mg}$ only, while the ones in blue are following additional implantation steps of the stable isotopes ${ }^{25} \mathrm{Mg}$ or ${ }^{26} \mathrm{Mg}$. Note the logarithmic scale for the $\mathrm{Mg}$ fluence. The concentrations of implanted $\mathrm{Mg}$ in the peak of the implantation profile are indicated at the top axes of the panels. 